Article

\title{
Preparation and Characterization of Silicon-Metal Fluoride Reactive Composites
}

\author{
Siva Kumar Valluri ${ }^{1}\left(\mathbb{D}\right.$, Mirko Schoenitz ${ }^{1}$ and Edward Dreizin ${ }^{1,2, * \mathbb{D}}$ \\ 1 O.H. York Department of Chemical and Materials Engineering, New Jersey Institute of Technology, \\ Newark, NJ 07102, USA; sv476@njit.edu (S.K.V.); schoenit@njit.edu (M.S.) \\ 2 High-Energy and Special Materials Research Laboratory, Tomsk State University, 634050 Tomsk, Russia \\ * Correspondence: dreizin@njit.edu
}

Received: 16 October 2020; Accepted: 25 November 2020; Published: 28 November 2020

\begin{abstract}
Fuel-rich composite powders combining elemental $\mathrm{Si}$ with the metal fluoride oxidizers $\mathrm{BiF}_{3}$ and $\mathrm{CoF}_{2}$ were prepared by arrested reactive milling. Reactivity of the composite powders was assessed using thermoanalytical measurements in both inert $(\mathrm{Ar})$ and oxidizing $\left(\mathrm{Ar} / \mathrm{O}_{2}\right)$ environments. Powders were ignited using an electrically heated filament; particle combustion experiments were performed in room air using a $\mathrm{CO}_{2}$ laser as an ignition source. Both composites showed accelerated oxidation of $\mathrm{Si}$ when heated in oxidizing environments and ignited readily using the heated filament. Elemental $\mathrm{Si}$, used as a reference, did not exhibit appreciable oxidation when heated under the same conditions and could not be ignited using either a heated filament or laser. Lower-temperature Si fluoride formation and oxidation were observed for the composites with $\mathrm{BiF}_{3}$; respectively, the ignition temperature for these composite powders was also lower. Particle combustion experiments were successful with the $\mathrm{Si} / \mathrm{BiF}_{3}$ composite. The statistical distribution of the measured particle burn times was correlated with the measured particle size distribution to establish the effect of particle sizes on their burn times. The measured burn times were close to those measured for similar composites with $\mathrm{Al}$ and $\mathrm{B}$ serving as fuels.
\end{abstract}

Keywords: reactive materials; nanocomposite; metal combustion; ignition; thermal analysis

\section{Introduction}

Silicon serves as a fuel in several pyrotechnic compositions [1]. Its high energy density, abundance in the lithosphere [2] and cheap manufacturing make it an attractive fuel for a broad range of applications, including propellants and explosives. However, it is known to be relatively difficult to burn [3,4]. Silicon has a high boiling point (3538 K) compared to its oxide (2503 K) and hence burns heterogeneously. Further, the nascent refractory oxide layer on silicon particles limits the inward diffusion of oxygen at temperatures below $1273 \mathrm{~K}$ [5]. The direct oxidation of silicon from gaseous oxygen [6] and nitrogen [7] is only accelerated at higher temperatures, when diffusion rates increase.

To make silicon more reactive, previous work focused on employing aggressive condensed phase oxidizers. Transition metal oxides [4,8-11], alkali metal nitrates [4,9-11], perchlorates [9] and manganates [9] were explored as oxidizers for micron-sized and nanometric silicon powders. These compositions, though favorably reactive, do not fully exploit the potential of silicon as they yield largely condensed phase combustion products. Respective silicon-condensed oxidizer composites have reduced energy content compared to elemental silicon reacting with oxygen gas; thus, the reactions have reduced adiabatic flame temperatures. Use of high surface area, porous nanosilicon has attracted attention [9,12-14]; however, such materials may be difficult to handle and their applications are mostly limited to pyrotechnics. 
In comparison to oxidation, fluorination of silicon is preferred in fuel-limited systems because the negative heat of formation of silicon tetrafluoride, $\mathrm{SiF}_{4},(-1615 \mathrm{~kJ} / \mathrm{mol})$ is substantially lower than that of $\mathrm{SiO}_{2}(-911 \mathrm{~kJ} / \mathrm{mol})$, making the reaction more exothermic. Silicon fluorides (and most oxyfluorides [15]) are gases under standard conditions.

Combustion-related work on fluorination of silicon was mostly limited to the use of fluoropolymers, e.g., polytetrafluoroethylene (PTFE) as oxidizers. Silicon-PTFE compositions are predicted to have a higher adiabatic combustion temperature and produce more gaseous products compared to combinations of silicon with oxide-based oxidizers [9]. Silicon-PTFE milled composites with a range of compositions (10-40 wt.\% silicon) have been explored [16-18].

In recent studies it was shown that metal fluorides, such as $\mathrm{CoF}_{2}, \mathrm{NiF}_{2}$ and $\mathrm{BiF}_{3}$, could be effective oxidizers with metal fuels, e.g., aluminum. Reduced ignition temperatures and higher burn rates than for pure aluminum (in air) were reported for respective composites [19,20]. Further, metal fluorides were combined with boron, known to be more difficult to ignite than aluminum. A marked improvement in the ignition and combustion characteristics for boron/metal fluoride composites was observed with as little as $10 \mathrm{wt} . \%$ of $\mathrm{BiF}_{3}$ [21,22]. The addition of fluorides altered combustion of boron particles: it occurred in a single stage with shortened burn times [21-23]. In constant volume explosion experiments, the $10 \mathrm{wt} . \% \mathrm{BiF}_{3}$ coated boron powders exhibited a higher rate of pressurization and higher maximum pressure compared to fine aluminum [22]. Experiments with aluminum and boron-based reactive composites containing metal fluorides as oxidizers show consistently significant improvements in kinetics of reactions leading to ignition $[24,25]$.

Despite the increased reactivity, the fluoride composites made with aluminum and boron were found to be safer to handle, as they were insensitive to electrostatic stimulus unlike oxide based compositions [24,25]. It should also be noted that the gas-phase fluorinated reaction products could be aggressive; thus care must be taken when such products are released.

The use of metal fluorides as oxidizers for silicon is explored in the current work. The fluorides used in this study, $\mathrm{BiF}_{3}$ and $\mathrm{CoF}_{2}$ were selected because they are less hygroscopic, easy to handle [25], and contain metals that interact differently with metal fuels: Bi does not alloy with most metals or metalloids while Co forms alloys readily. The phase of the reduced metal (pure element or alloy) could affect further oxidation and combustion reactions. Based only on gravimetric and volumetric heats of reaction shown in Table 1 , replacing oxides of $\mathrm{Co}$ and $\mathrm{Bi}$ with respective fluorides does not lead to tangible advantages. The heats of reactions are nearly matching for the metal-rich composites (with $50 \mathrm{wt}$ \% of $\mathrm{Si}$ ) reacting in presence of the external oxidizer, so that excess of $\mathrm{Si}$ and the metals obtained from the reduced fluorides can further be oxidized. Thus, the anticipated advantages of using metal fluorides are not based on the expected theoretical energy release but are based on the expected accelerated reaction rates and formation of gas phase products.

Table 1. Estimated heats of reactions involving $\mathrm{Si}$ with oxides and fluorides of $\mathrm{Co}$ and $\mathrm{Bi}$ for stoichiometric and fuel-rich (50/50 wt.\%) composites reacting in inert and oxidizing environments.

\begin{tabular}{|c|c|c|c|c|}
\hline & \multirow{2}{*}{\multicolumn{2}{|c|}{ Composite Type }} & \multicolumn{2}{|c|}{ Heat of Reaction } \\
\hline & & & $\mathrm{kJ} / \mathrm{g}$ & $\mathrm{kJ} / \mathrm{cm}^{3}$ \\
\hline \multirow{6}{*}{$\begin{array}{l}\text { Si with } \mathrm{Bi}_{2} \mathrm{O}_{3} \text { and } \\
\mathrm{BiF}_{3}\end{array}$} & \multirow{2}{*}{ Stoichiometric } & $3 \mathrm{Si}+2 \mathrm{Bi}_{2} \mathrm{O}_{3} \rightarrow 3 \mathrm{SiO}_{2}+4 \mathrm{Bi}$ & -1.56 & -11.25 \\
\hline & & $3 \mathrm{Si}+4 \mathrm{BiF}_{3} \rightarrow 3 \mathrm{SiF}_{4}+4 \mathrm{Bi}$ & -1.05 & -5.12 \\
\hline & \multirow{4}{*}{$\begin{array}{l}50 / 50 \text { wt. } \% \text { (fuel } \\
\text { rich) * }\end{array}$} & $\mathrm{Si}+\mathrm{Bi}_{2} \mathrm{O}_{3} \rightarrow \mathrm{Si}+\mathrm{SiO}_{2}+\mathrm{Bi}$ & -0.85 & -3.14 \\
\hline & & $\mathrm{Si}+\mathrm{BiF}_{3} \rightarrow \mathrm{Si}+\mathrm{SiF}_{4}+\mathrm{Bi}$ & -0.57 & -1.84 \\
\hline & & $\begin{array}{c}\text { Added ambient oxidizer } \\
\mathrm{Si}+\mathrm{Bi}_{2} \mathrm{O}_{3}+\mathrm{O}_{2} \rightarrow \mathrm{SiO}_{2}+\mathrm{Bi}_{2} \mathrm{O}_{3}\end{array}$ & -15.6 & -57.6 \\
\hline & & $\begin{array}{c}\text { Added ambient oxidizer } \\
\mathrm{Si}+\mathrm{BiF}_{3}+\mathrm{O}_{2} \rightarrow \mathrm{SiF}_{4}+\mathrm{SiO}_{2}+\mathrm{Bi}_{2} \mathrm{O}_{3}\end{array}$ & -15.5 & -50.22 \\
\hline
\end{tabular}


Table 1. Cont.

\begin{tabular}{|c|c|c|c|c|}
\hline & \multicolumn{2}{|c|}{ Composite Type } & \multicolumn{2}{|c|}{ Heat of Reaction } \\
\hline & & & $\mathrm{kJ} / \mathrm{g}$ & $\mathrm{kJ} / \mathrm{cm}^{3}$ \\
\hline \multirow{6}{*}{$\begin{array}{l}\text { Si with } \mathrm{CoO} \text { and } \\
\mathrm{CoF}_{2}\end{array}$} & \multirow{2}{*}{ Stoichiometric } & $\mathrm{Si}+2 \mathrm{CoO} \rightarrow \mathrm{SiO}_{2}+2 \mathrm{Co}$ & -2.45 & -12.32 \\
\hline & & $\mathrm{Si}+2 \mathrm{CoF}_{2} \rightarrow \mathrm{SiF}_{4}+2 \mathrm{Co}$ & -1.28 & -5.11 \\
\hline & \multirow{4}{*}{$\begin{array}{l}50 / 50 \text { wt. } \% \\
\text { (fuel-rich) * }\end{array}$} & $\mathrm{Si}+\mathrm{CoO} \rightarrow \mathrm{Si}+\mathrm{SiO}_{2}+\mathrm{Co}$ & -1.45 & -4.97 \\
\hline & & $\mathrm{Si}+\mathrm{CoF}_{2} \rightarrow \mathrm{Si}+\mathrm{SiF}_{4}+\mathrm{Co}$ & -0.60 & -1.82 \\
\hline & & $\begin{array}{c}\text { Added ambient oxidizer } \\
\mathrm{Si}+\mathrm{CoO}+\mathrm{O}_{2} \rightarrow \mathrm{SiO}_{2}+\mathrm{CoO}\end{array}$ & -14.63 & -50.05 \\
\hline & & $\begin{array}{c}\text { Added ambient oxidizer } \\
\mathrm{Si}+\mathrm{CoF}_{2}+\mathrm{O}_{2} \rightarrow \mathrm{SiF}_{4}+\mathrm{SiO}_{2}+\mathrm{CoO}\end{array}$ & -14.46 & -44.26 \\
\hline
\end{tabular}

* For clarity of the concept, reactions are written without balancing reactants and products.

Both $\mathrm{BiF}_{3}$ and $\mathrm{CoF}_{2}$ were incorporated into silicon-metal fluoride composites prepared by arrested reactive milling [26].

\section{Experimental}

\subsection{Materials Preparation}

The silicon-metal fluoride composite powders were prepared in a SPEX Certiprep 8000 series shaker mill (by SPEX CertiPrep, Metuchen, NJ, USA). The constituent silicon (-325 mesh crystalline $\mathrm{Si}, 99 \%$ ) and anhydrous fluoride powders, bismuth (III) fluoride ( $\mathrm{BiF}_{3}, 98 \%$ ) and cobalt (II) fluoride $\left(\mathrm{CoF}_{2}, 99 \%\right)$ were sourced from Alfa Aesar, Ward Hill, MA, USA. Preliminary inspection using electron microscopy showed that $\mathrm{BiF}_{3}$ contained crystalline particle agglomerates, mostly in the 10-15 $\mu \mathrm{m}$ range. For $\mathrm{CoF}_{2}$, the powder appeared as finer powder, with most particles in the single micron range. The compositions targeted 30 and $50 \mathrm{wt}$.\% of silicon with the remaining mass of bismuth or cobalt fluoride. The materials were prepared in $5 \mathrm{~g}$ batches in steel milling vials. The powders were milled using steel milling media with hexane as the process control agent. The ball to powder mass ratio was fixed at 10 .

In an initial, exploratory experiment, $50 \mathrm{wt} . \%$ silicon and $50 \mathrm{wt} . \%$ bismuth fluoride were milled for $60 \mathrm{~min}$ using $9.25-\mathrm{mm}$ (3/8 in) diameter steel balls with $7 \mathrm{~mL}$ of hexane. This material is referred to as 1 -stage $50 \mathrm{Si} \cdot 50 \mathrm{BiF}_{3}$. Examination of 1 -stage $50 \mathrm{Si} \cdot 50 \mathrm{BiF}_{3}$ samples showed the presence of large Si particles that were not mixed with $\mathrm{BiF}_{3}$. To improve homogeneity, milling was therefore carried out it two steps for all other prepared composites. Silicon was milled separately in the first milling step to refine it. This step lasted $60 \mathrm{~min}$ and used $14 \mathrm{~mL}$ of hexane and 5-mm steel balls. This size-reduced silicon was also used as reference material for thermal analysis and other experiments.

In the second step, the size-reduced (premilled) silicon was milled with bismuth fluoride or cobalt fluoride for $60 \mathrm{~min}$ using 4.76-mm steel balls with $7 \mathrm{~mL}$ of hexane. These composites are referred to as $50 \mathrm{Si} \cdot 50 \mathrm{BiF}_{3}, 50 \mathrm{Si} \cdot 50 \mathrm{CoF}_{2}, 30 \mathrm{Si} \cdot 70 \mathrm{BiF}_{3}$ and $30 \mathrm{Si} \cdot 70 \mathrm{CoF}_{2}$, with respective mass percentages of components used as identifiers. Table 2 presents characteristics of the prepared materials. The equivalence ratios describe reactions.

$$
\mathrm{Si}+\frac{4}{x} \mathrm{MeF}_{x} \rightarrow \mathrm{SiF}_{4} \uparrow+\frac{4}{x} \mathrm{Me}
$$

where Me stands for Bi or Co. Reactions (1) reduce the respective metal fluorides and yield $\mathrm{SiF}_{4}$. All prepared composites are fuel-rich, making them potential fuel candidates for applications where oxygenated gas environments are available. 
Table 2. Compositions of prepared silicon-metal fluoride reactive composites.

\begin{tabular}{|c|c|c|c|c|c|}
\hline \multirow{2}{*}{$\begin{array}{l}\text { Milling } \\
\text { Protocol }\end{array}$} & \multirow{2}{*}{ Material } & \multirow{2}{*}{$\begin{array}{c}\text { Fluoride } \\
\text { Volume (\%) }\end{array}$} & \multirow{2}{*}{$\begin{array}{c}\text { Equivalence } \\
\text { Ratio } \phi\end{array}$} & \multicolumn{2}{|c|}{ Mass of Fluorine (\%) } \\
\hline & & & & Prepared & Stoichiometric \\
\hline \multirow{2}{*}{ Single stage } & 1-stage & & & & \multirow{4}{*}{19.9} \\
\hline & $50 \mathrm{Si} \cdot 50 \mathrm{BiF}_{3}$ & 30.4 & 12.6 & 10.7 & \\
\hline \multirow{4}{*}{ Two stages } & $50 \mathrm{Si} \cdot 50 \mathrm{BiF}_{3}$ & & & & \\
\hline & $30 \mathrm{Si} \cdot 70 \mathrm{BiF}_{3}$ & 50.5 & 5.4 & 15 & \\
\hline & $50 \mathrm{Si} \cdot 50 \mathrm{CoF}_{2}$ & 34.3 & 6.9 & 19.6 & \multirow{2}{*}{34.2} \\
\hline & $30 \mathrm{Si} \cdot 70 \mathrm{CoF}_{2}$ & 54.9 & 3.0 & 27.4 & \\
\hline
\end{tabular}

The prepared materials were passivated in an argon-filled glovebox, where oxygen was present at a low partial pressure. The passivation lasted $48 \mathrm{~h}$. Passivated materials were covered by hexane and stored in the laboratory for the duration of this project.

Reactivity was initially assessed by taking $100-200 \mathrm{mg}$ of powder on a ventilated filter paper and igniting the paper by a butane lighter inside a fume hood. The $30 \mathrm{wt} . \%$ silicon powders burned quickly with a bright noiseless flash; the $50 \mathrm{wt} . \%$ silicon powders were comparatively slower and generated particle streaks jetting from the burning powder bulk. For the $50 \mathrm{wt} . \%$ silicon compositions, despite a coarser scale of mixing and poor homogeneity, 1-stage $50 \mathrm{Si} \cdot 50 \mathrm{BiF}_{3}$ was visibly more reactive than two-stage milled $50 \mathrm{Si} \cdot 50 \mathrm{BiF}_{3}$. There was no apparent difference between composites with $\mathrm{BiF}_{3}$ and $\mathrm{CoF}_{2}$ serving as oxidizers.

\subsection{Material Characterization}

The surface morphology and homogeneity of mixing between components in the prepared powders was examined using a JSM-7900 field emission scanning electron microscope (SEM) by JEOL, Tokyo, Japan. The imaging was performed by back-scattered electrons to achieve compositional contrast. To identify material composition and impurities incorporated by milling, energy dispersive X-ray spectroscopy (EDX) was used. The prepared powders were also analyzed using X-ray diffraction (XRD) on a PANalytical Empyrean multipurpose research diffractometer by Malvern Panalytical, Malvern, $\mathrm{UK}$, operated at $45 \mathrm{kV}$ and $40 \mathrm{~mA}$ using filtered $\mathrm{Cu} \mathrm{K}_{\alpha}$ radiation.

Reactivity of powders containing $50 \mathrm{wt} . \%$ silicon was tested by thermogravimetric analysis (TG) coupled with differential thermal analysis (DTA)/differential scanning calorimetry (DSC) on a STA409PG by Netzsch, Selb, Germany. The powders with a composition of $30 \mathrm{wt} . \%$ silicon were not tested to avoid releasing large amounts of aggressive fluorinated gases in the instrument.

Samples were heated in open alumina DTA crucibles only up to $973 \mathrm{~K}\left(700^{\circ} \mathrm{C}\right)$ to limit release of volatile fluorinated species. Samples were tested in argon (99.998\%) flowing at $50 \mathrm{~mL} / \mathrm{min}$ as an inert environment and in an oxidizing environment, with an additional $50 \mathrm{~mL} / \mathrm{min}$ flow of oxygen (99.994\%). Both gases were sourced from Airgas. For each case, a baseline was obtained by heating an empty crucible under identical conditions. The sample mass was fixed at $5 \mathrm{mg}$, except for a few runs in argon performed with larger sample masses of 10 and $24 \mathrm{mg}$. For the oxidizing environment, heating rates 1,2 and $5 \mathrm{~K} / \mathrm{min}$ were used. Experiments in argon were performed with heating rates of 2, 5 and $10 \mathrm{~K} / \mathrm{min}$. To probe the progress of reactions, samples were recovered from specific intermediate temperatures and analyzed using XRD.

\subsection{Heated Filament Ignition}

The ignition temperatures for the prepared powders were obtained by coating a sample onto an electrically heated 24 gauge $(0.5105 \mathrm{~mm})$ nickel-chromium wire. The time of ignition was determined from a high-speed video and the wire temperature was measured optically, using a calibrated photo diode. The basic experimental setup and procedure have been presented earlier [27]. 
The photodiode-based pyrometer has been described in Ref. [24]. Briefly, the wire was coated with a suspension of the powder in hexane. Once the hexane dried, the wire was electrically heated using a variable set of rechargeable large cell batteries (7238K57 McMaster Carr. Elmhurst, IL, USA) and a $1 \Omega$ rheostat connected in series to achieve targeted heating rates in the range of $10^{3}-10^{4} \mathrm{~K} / \mathrm{s}$. A fiber optics cable was focused at a section of the wire that was uncoated and fed into germanium photodiode (PDA30B2 by Thorlabs, Newton, NJ, USA). The photodiode was calibrated against a black body emission source (BB4A by Omega Engineering, Bridgeport, NJ, USA) to function as a high-speed pyrometer. To correlate the time of ignition to the temperature of the wire, the ignition was recorded using a MotionPro 500 camera by Redlake, San Diego, CA, USA, synchronized with the ignition circuit. At least 5 runs were performed for each targeted heating rate.

\subsection{Particle Combustion}

The particle combustion was studied by aerosolizing the materials in a room-temperature air stream fed into the focal spot of a sealed $\mathrm{CO}_{2}$ laser (Evolution 125 by Synrad, Mukilteo, WA, USA). The optical emission of the ignited particles was captured by filtered photomultiplier tubes (PMT) to obtain burn times. Each burning particle produced an emission pulse; the pulse width taken at $10 \%$ of its peak value was interpreted as the burn time.

The powder feeder described elsewhere [28] consisted of a screw driven by a DC motor, with 30 threads coated by $0.12 \mathrm{~g}$ of powder. The powder lodged between the threads was blown off the screw and aerosolized by a carrier gas, air flown at $0.68 \mathrm{~L} / \mathrm{min}$. The aerosolized particles were fed via a $2.39 \mathrm{~mm}$ internal diameter brass tube. The upper end of the tube was placed $2 \mathrm{~mm}$ below the focal spot of the laser. The laser beam was focused by a ZnS lens to a spot of about $250 \mu \mathrm{m}$ diameter. The laser was operated at $37.5 \mathrm{~W}$, or ca. $30 \%$ of its maximum power, which is much higher than the ignition threshold for the materials tested. Thus, particles passing through the laser beam ignited consistently. Further experimental details are available elsewhere [29].

A fiber optics bundle trained to capture the particle emissions was placed $2 \mathrm{~cm}$ above and $16 \mathrm{~cm}$ away from the brass feeder tube. The fiber was split to feed to two R3896-03 PMTs by Hamamatsu, Hamamatsu City, Japan, filtered at 700 and $800 \mathrm{~nm}$. The signal from the PMTs was acquired through a 16 bit PCI-6123 board by National Instruments, Austin, TX, USA, at 100,000 samples per second and processed using LabView software (Labview 16 by National Instruments, August 2016). Signal was collected for periods of $8 \mathrm{~s}$ at a time. Several such $8 \mathrm{~s}$ runs were required to acquire over 800 pulses produced by individual burning particles for each material. Overlapping, or closely spaced pulses were dismissed. The widths of the collected individual particle pulses, interpreted as burn times, were developed into respective statistical distributions employing a smoothing kernel density function [21].

\subsection{Aerosolized Particle Collection and Sizing}

The aerosolization of the composite powders may cause size classification. Thus, the size distributions for the particles observed to burn in the present experiments could differ from those of the prepared powders. To account for this, samples of powders passed through the feeder were collected and analyzed. A flat aluminum substrate covered with a double-sided adhesive carbon tape was placed $2.5 \mathrm{~cm}$ above the brass feeder. Particles were trapped onto the tape for 10-15 $\mathrm{s}$ using the feeder operated at the same gas flowrate as in the combustion tests; however, with the laser beam turned off. The collected particles were imaged by the SEM and their sizes were obtained using ImageJ software [30]. From a table of all particles of one material, size distributions were generated using a kernel density function. The particle size distributions were correlated with the burn time distributions to identify the effect of particle size on the burn time. Such correlations broadly assume that larger particles burn longer. 


\section{Results}

\subsection{Particle Morphology and Composition}

SEM images of the prepared $50 \mathrm{wt} . \%$ silicon- $50 \mathrm{wt} . \%$ metal fluoride composites are presented in Figure 1 . The grey crystalline phase was silicon, and the brightest phase was the fluoride. The carbon tape in the background appeared darkest. The single stage milled 1-stage $50 \mathrm{Si} \cdot 50 \mathrm{BiF}_{3}$ powder is shown in Figure 1A,B. It is apparent from Figure 1A that the fluoride was not uniformly distributed in the material. Many relatively large, ca. $20-40 \mu \mathrm{m}$, Si particles and some unattached $\mathrm{BiF}_{3}$ clusters were observed. Part of the image in Figure 1A with a relatively well-homogenized composite particle was magnified and shown as Figure $1 \mathrm{~B}$. Individual $\mathrm{Si}$ and $\mathrm{BiF}_{3}$ phases were interspersed on a submicron scale. Such particles were few with a majority of silicon particles having little to no fluoride attached to them.
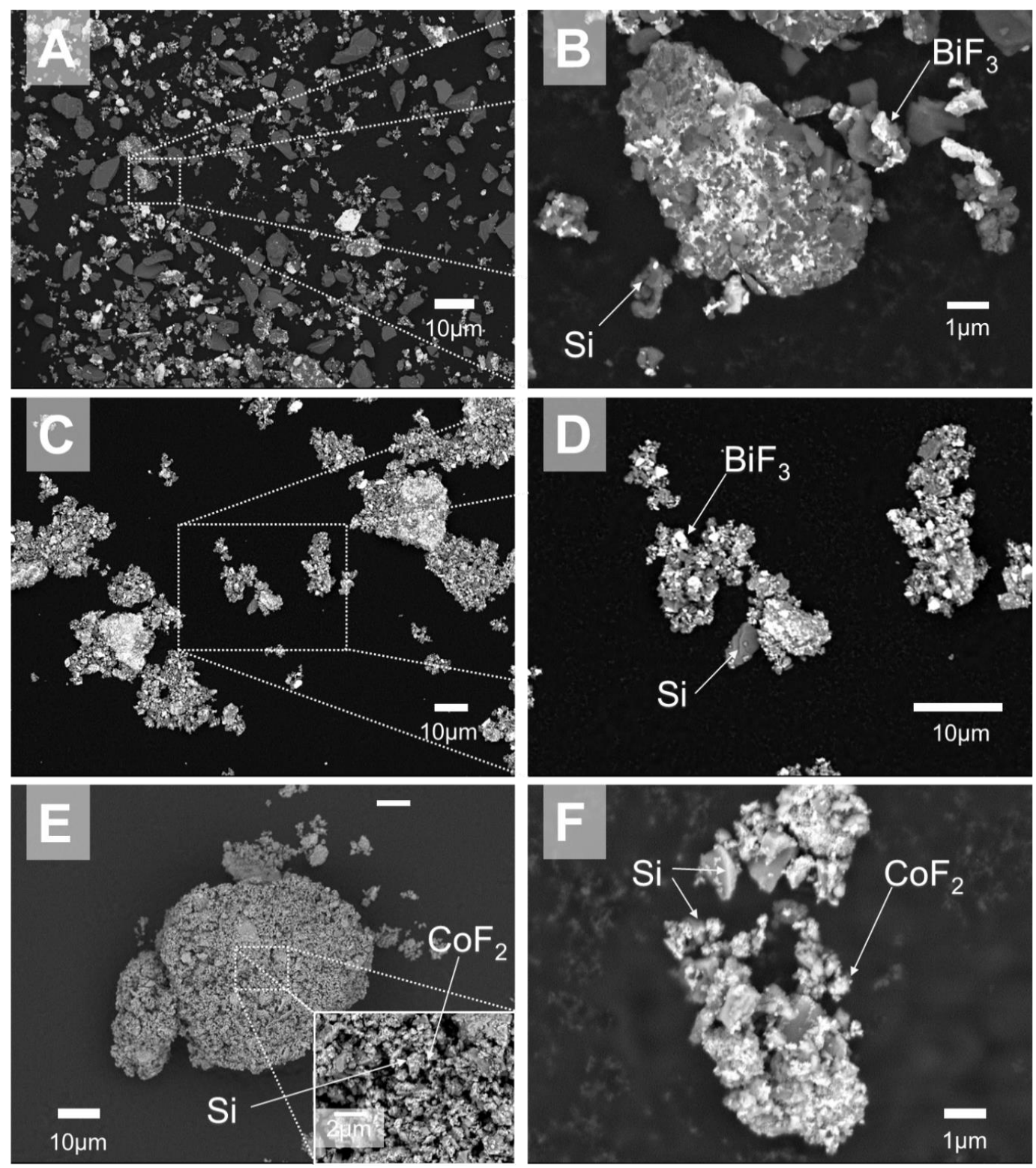

Figure 1. Backscattered electron images of as-milled $50 \mathrm{wt} . \%$ silicon-50 wt.\% fluoride composites: (A,B) 1-stage 50Si·50BiF $3,\left(\right.$ C,D) $50 \mathrm{Si} \cdot 50 \mathrm{BiF}_{3}$ and $(\mathbf{E}, \mathbf{F}) 50 \mathrm{Si} \cdot 50 \mathrm{CoF}_{2}$. 
A composite prepared using the two-stage protocol, $50 \mathrm{Si} \cdot 50 \mathrm{BiF}_{3}$ is shown in Figure $1 \mathrm{C}, \mathrm{D}$. All particles show good mixing of the fluoride and silicon and reduced particle sizes in Figure $1 C$. A magnified image of a representative particle in Figure 1D shows angular silicon crystals decorated by bright particles of $\mathrm{BiF}_{3}$.

The images of the two-stage milled $50 \mathrm{Si} \cdot 50 \mathrm{CoF}_{2}$ powder are presented in Figure 1E,F. In Figure $1 \mathrm{E}$, a large, agglomerated particle of $60 \mu \mathrm{m}$, with no discernable difference in phase contrast is seen. Such agglomerates were common. The inset in Figure 1E shows that the particle surface had distinct angular platelets and smaller particles. Through EDX, the larger platelets were confirmed to be Si and the smaller particles were found to be $\mathrm{CoF}_{2}$. A smaller particle of $50 \mathrm{Si} \cdot 50 \mathrm{CoF}_{2}$ is shown in Figure $1 \mathrm{~F}$. Distinct morphology enables one to identify both silicon and $\mathrm{CoF}_{2}$ phases mixed rather uniformly on the nanoscale.

SEM images of powders with $30 \mathrm{wt} . \%$ silicon and $70 \mathrm{wt} \%$ metal fluoride are presented in Figure 2. These images were obtained using secondary electrons to highlight the surface morphology, while losing on the phase contrast. General particle morphology for $30 \mathrm{Si} \cdot 70 \mathrm{BiF}_{3}$ is illustrated in Figure 2A,B. Similarly, the morphology for $30 \mathrm{Si} \cdot 70 \mathrm{CoF}_{2}$ is illustrated by Figure $2 \mathrm{C}, \mathrm{D}$.
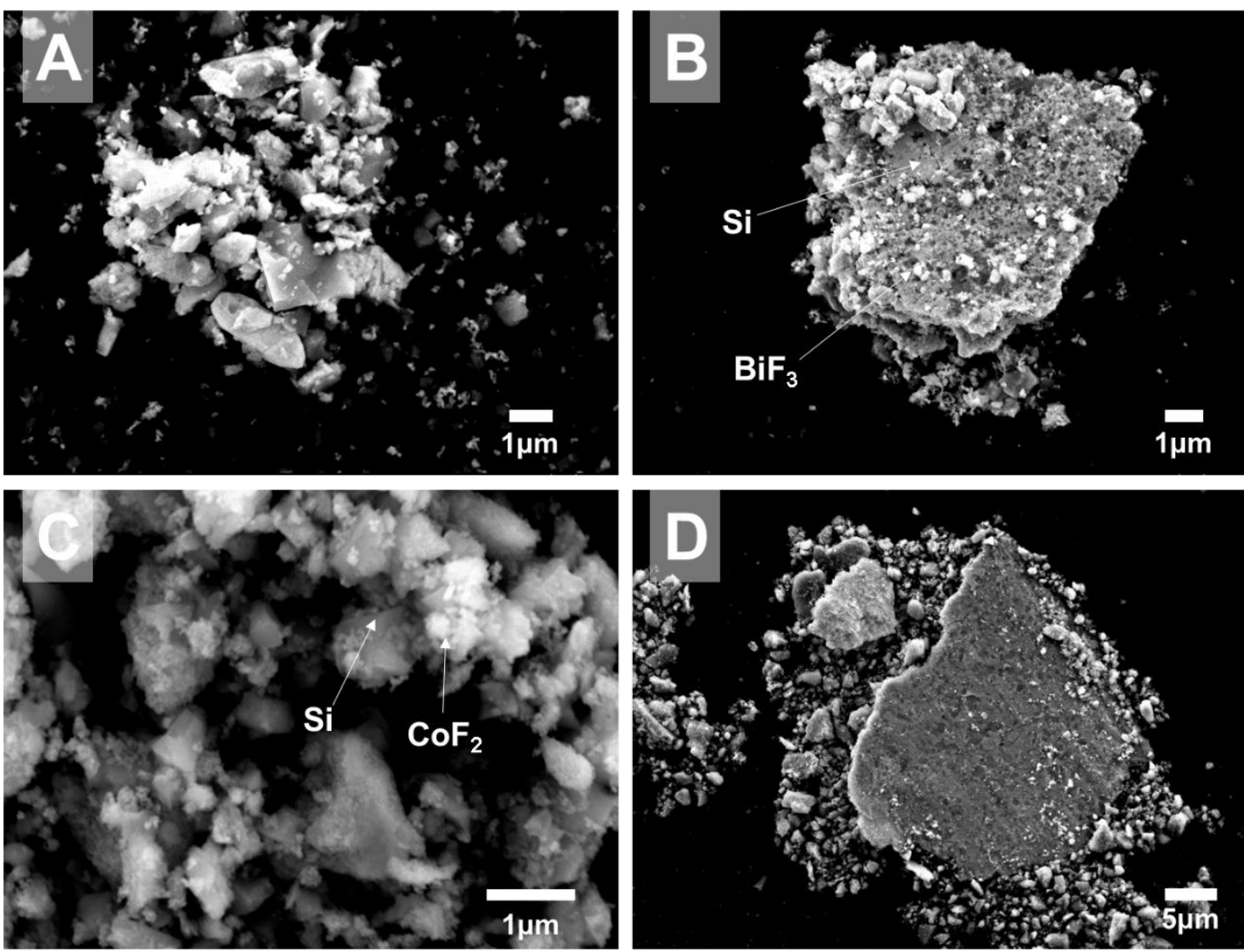

Figure 2. Secondary electron images of as milled $30 \mathrm{wt} . \%$ silicon-70 wt.\% fluoride composites: $(\mathbf{A}, \mathbf{B}) 30 \mathrm{Si} \cdot 70 \mathrm{BiF}_{3}$ and $(\mathbf{C , D}) 30 \mathrm{Si} \cdot 70 \mathrm{CoF}_{2}$

A large amount of unattached $\mathrm{BiF}_{3}$ particles and small crystalline silicon particles were observed in Figure $2 \mathrm{~A}$. Some relatively large $\mathrm{BiF}_{3}$ particles decorated agglomerates of silicon crystals (Figure 2B); although the coating did not appear to be uniform.

In Figure 2C, cobalt fluoride was observed as small fuzzy particles covering jagged crystals of silicon. No unattached $\mathrm{CoF}_{2}$ was observed. Generally, $30 \mathrm{Si} \cdot 70 \mathrm{CoF}_{2}$ composite contained silicon particles with a broad size distribution and all Si surfaces were rather uniformly coated by cobalt fluoride, unlike $30 \mathrm{Si} \cdot 70 \mathrm{BiF}_{3}$. Occasional large particles $(>10 \mu \mathrm{m})$ were observed in both materials, as 
shown in Figure 2B,D. A flat surface, typically formed by milling balls pressing into a softer material, was commonly observed for such particles. SEM images show that such large particles consisted of fine silicon particles embedded in a fluoride matrix.

The XRD patterns of milled composites are presented in Figure 3. Peaks corresponding to $\mathrm{BiF}_{3}$ and $\mathrm{Bi}_{7} \mathrm{~F}_{11} \mathrm{O}_{5}$ [31] were observed in all Bi-containing composites. Detectable amounts of reduced $\mathrm{Bi}$ were also observed. In the two-stage milled composites, the fluoride and reduced Bi peak intensities scale with the loaded $\mathrm{BiF}_{3}$ concentration; stronger fluoride peaks were observed for $30 \mathrm{Si}^{\circ} \cdot 70 \mathrm{BiF}$ as compared to $50 \mathrm{Si} \cdot 50 \mathrm{BiF}_{3}$. Results of quantitative composition analysis for $\mathrm{BiF}_{3}$-containing composites based on the whole pattern refinement performed using the X-pert Highscore software package [32] are shown in Table 3 . The data suggest that $50 \mathrm{Si} \cdot 50 \mathrm{BiF}_{3}$ retained only ca. $64 \%$ of the initial fluorine. On the other hand, the poorly refined 1-stage $50 \mathrm{Si} \cdot 50 \mathrm{BiF}_{3}$ exhibited the weakest bismuth peaks and strongest $\mathrm{BiF}_{3 /} \mathrm{Bi}_{7} \mathrm{~F}_{11} \mathrm{O}_{5}$ peaks among the three $\mathrm{Si} \cdot \mathrm{BiF}_{3}$ composites; it retained approximately $71 \%$ if the initial fluorine.

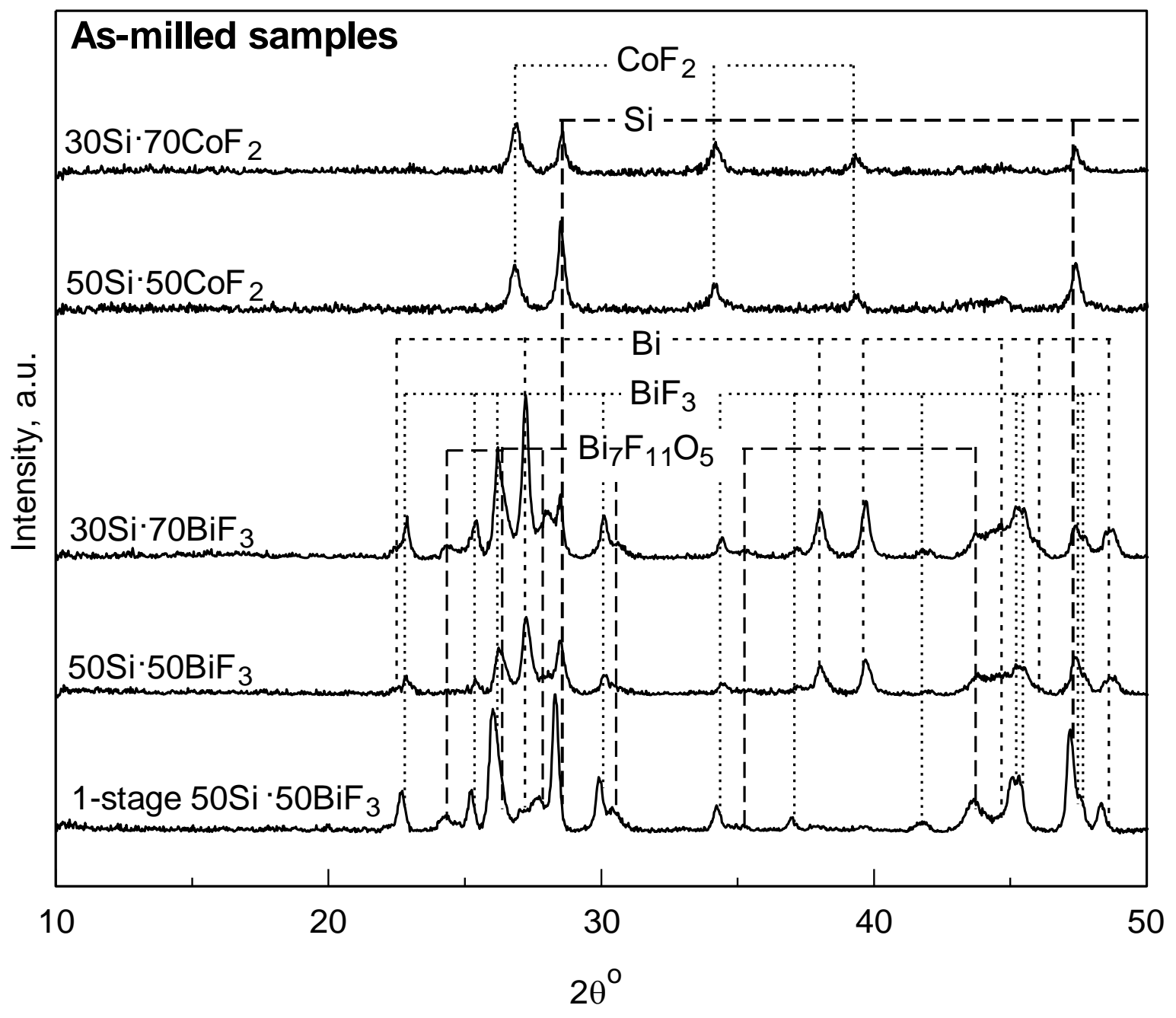

Figure 3. XRD patterns of the prepared composite powders.

The XRD pattern of the composites with $\mathrm{CoF}_{2}$ shows peaks corresponding to silicon and cobalt fluoride. No reduced cobalt is observed. The scaling of the fluoride peak intensity as a function of the loaded fluoride concentration was less apparent. 
Table 3. Compositions of the prepared $\mathrm{Si} \cdot \mathrm{BiF}_{3}$ composites obtained from the whole pattern refinement of the XRD traces.

\begin{tabular}{cccccc}
\hline \multirow{2}{*}{ Sample } & $\mathbf{5}$ Mass (\%) \\
\cline { 2 - 6 } & $\mathbf{S i}$ & $\mathbf{B i}$ & $\mathbf{B i F}_{\mathbf{3}}$ & $\mathbf{B i F}_{\mathbf{1 . 5 7}} \mathbf{O}_{\mathbf{0 . 7 1}}$ & $\mathbf{B i F}_{\mathbf{1 . 9 8}} \mathbf{O}_{\mathbf{0 . 5 1}}$ \\
\hline 1-stage-50Si-50BiF & 55.2 & 1.7 & 22.4 & 9.7 & 11.0 \\
\hline 50Si-50BiF & 45.6 & 12.0 & 16.6 & 17.3 & 8.5 \\
\hline 30Si-70BiF & 26.6 & 16.4 & 24.9 & 20.8 & 11.3 \\
\hline
\end{tabular}

\subsection{Thermal Analysis}

The TG and their corresponding DTA traces for $50 \mathrm{Si} \cdot 50 \mathrm{CoF}_{2}$ heated in both oxidizing and inert environments are shown in Figure 4. The DTA traces for the oxidizing and inert runs used separate vertical scales because of difference in the heat effects observed. The TG trace measured in Ar (Figure 4A) shows a single mass loss event with the onset below $673 \mathrm{~K}\left(400{ }^{\circ} \mathrm{C}\right)$; the total observed mass loss was close to $23 \%$ of the initial mass. The respective DTA trace (Figure $4 \mathrm{~B}$ ) shows weak features, which can be interpreted at two broad exothermic humps (peaks at 498 and $893 \mathrm{~K}$ (or 225 and $620{ }^{\circ} \mathrm{C}$ )) or a very broad exothermic feature overlaid with an endothermic event. To support the latter interpretation, much of the endothermic feature correlated with the observed mass loss.

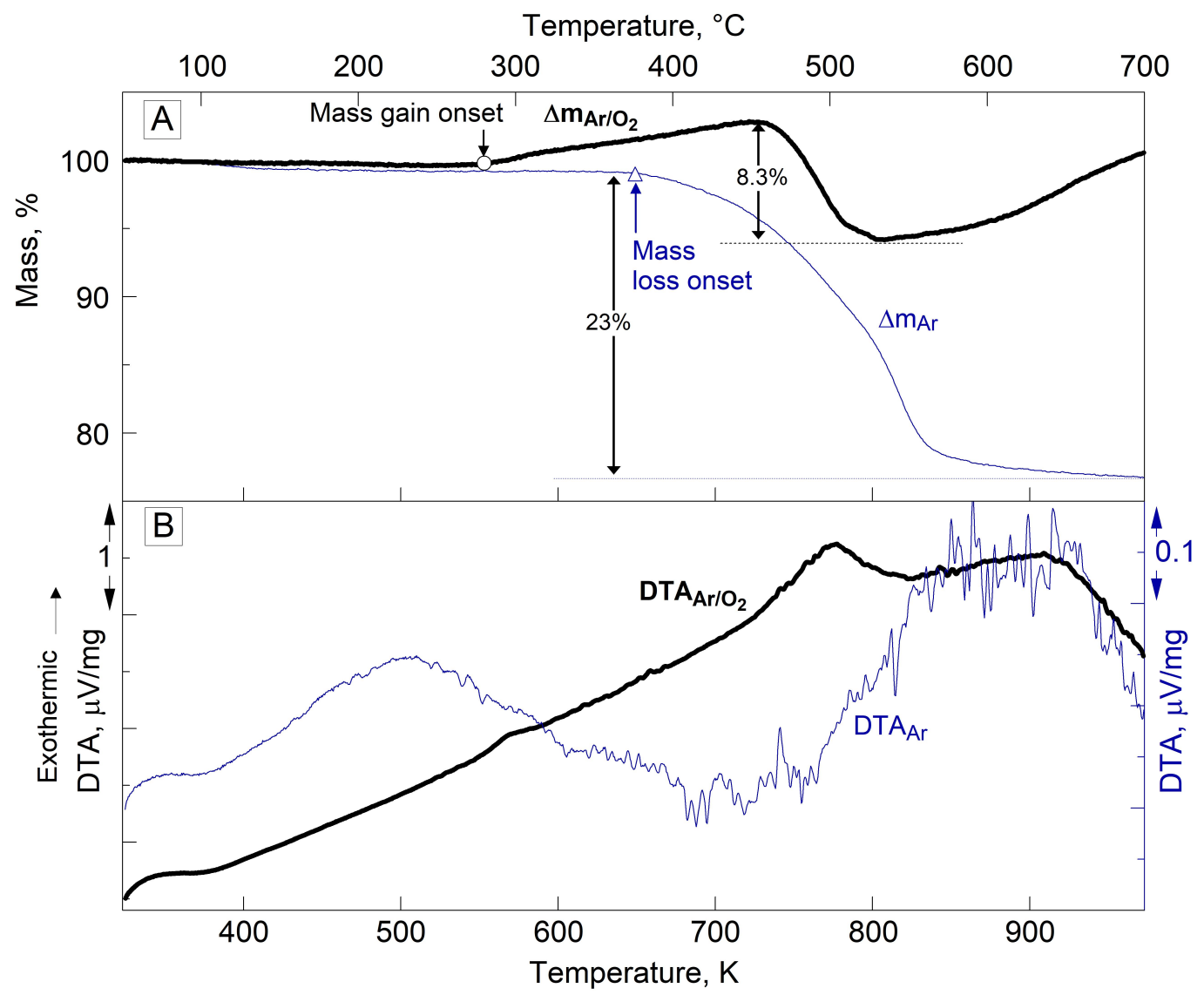

Figure 4. (A) Thermogravimetric analysis (TG) and corresponding (B) differential thermal analysis (DTA) traces for $50 \mathrm{Si} \cdot 50 \mathrm{CoF}_{2}$ heated at $5 \mathrm{~K} / \mathrm{min}$ in different environments.

For TG in $\mathrm{Ar} / \mathrm{O}_{2}$, the onset for a gradual mass gain was at $548 \mathrm{~K}\left(275^{\circ} \mathrm{C}\right)$. The mass gain was reversed at $723 \mathrm{~K}\left(450{ }^{\circ} \mathrm{C}\right)$, and the maximum mass loss of ca. $8.3 \%$ was observed by $798 \mathrm{~K}\left(525^{\circ} \mathrm{C}\right)$. After the minimum, the mass began increasing again. The corresponding DTA trace exhibited a rising baseline (despite the correction applied using an empty crucible). A small exothermic peak was noted 
at $280{ }^{\circ} \mathrm{C}$, corresponding to the onset of the mass gain. A stronger exotherm was observed at $773 \mathrm{~K}$ $\left(500^{\circ} \mathrm{C}\right)$ correlating with the mass loss.

The TG and DTA plots for $50 \mathrm{Si} \cdot 50 \mathrm{BiF}_{3}$ heated in different environments are presented in Figure 5. In Figure 5A, the oxidative TG runs for the milled/size-reduced Si and 1-stage $50 \mathrm{Si}^{-50 \mathrm{BiF}_{3}} \mathrm{were}$ presented for comparison. No mass change is observed for the Si reference.

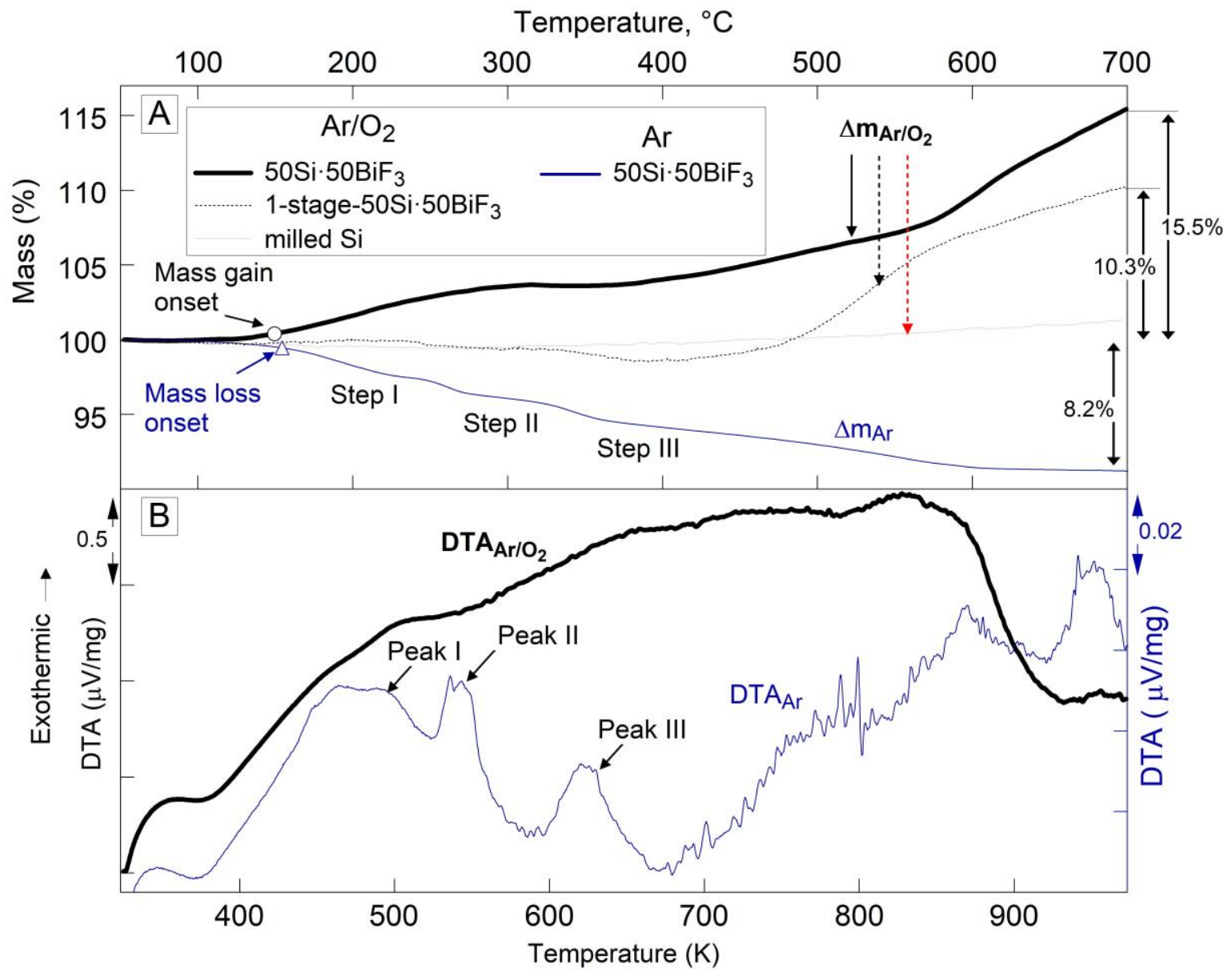

Figure 5. (A) TG and corresponding (B) DTA traces for $50 \mathrm{Si} \cdot 50 \mathrm{BiF}_{3}$ in heated at $5 \mathrm{~K} / \mathrm{min}$ in oxidizing and inert environments. The oxidative TG runs for 1-stage $50 \mathrm{Si} \cdot 50 \mathrm{BiF}_{3}$ and milled $\mathrm{Si}$ are also shown.

The TG trace for $50 \mathrm{Si} \cdot 50 \mathrm{BiF}_{3}$ in Ar shows a gradual mass loss of $8.2 \%$. It begins around $423 \mathrm{~K}$ $\left(150{ }^{\circ} \mathrm{C}\right)$ and ends by $873 \mathrm{~K}\left(600^{\circ} \mathrm{C}\right)$. Weak but reproducible step-like features are noted in the TG trace; the onset for the mass loss are marked by a filled circle as labeled in Figure 5A. The corresponding DTA plot in Figure 5B, shows multiple weak peaks. It is possible to interpret the trace as showing a broad endothermic peak, similar to that in Figure 4. Additionally, several exothermic features are noted. The first three of these features, labeled in Figure 5B, correlated with the mass loss steps. The second exotherm, at ca. $543 \mathrm{~K}\left(270{ }^{\circ} \mathrm{C}\right.$; marked Peak II), had a small but reproducible superimposed endothermic feature.

For $50 \mathrm{Si} \cdot 50 \mathrm{BiF}_{3}$ experiments in both $\mathrm{Ar}$ and $\mathrm{Ar} / \mathrm{O}_{2}$ were performed at different heating rates. The shift of the respective mass loss and mass gain points to higher temperatures at greater heating rates was used to consider relevance of the respective reactions to ignition, as discussed below.

In $\mathrm{Ar} / \mathrm{O}_{2}$, 1-stage milled $50 \mathrm{Si} \cdot 50 \mathrm{BiF}_{3}$, exhibited a small mass loss (ca. $1.5 \%$, onset at $583 \mathrm{~K}\left(310{ }^{\circ} \mathrm{C}\right)$ ) and then mass gain, which was not complete by the end of the run. For the two-stage milled composite, $50 \mathrm{Si} \cdot 50 \mathrm{BiF}_{3}$, heated in $\mathrm{Ar} / \mathrm{O}_{2}$, the mass began to increase at ca. $423 \mathrm{~K}\left(150^{\circ} \mathrm{C}\right)$ as marked in Figure $5 \mathrm{~A}$. The mass was stabilized by about $593 \mathrm{~K}\left(320^{\circ} \mathrm{C}\right)$. It began increasing again at $658 \mathrm{~K}\left(385{ }^{\circ} \mathrm{C}\right)$; the rate of mass gain increased around $873 \mathrm{~K}\left(600^{\circ} \mathrm{C}\right)$. The final measured mass gain was $15.5 \%$, it was not 
complete by the end of the run. The corresponding DTA curve for $50 \mathrm{Si} \cdot 50 \mathrm{BiF}_{3}$ seen in Figure $5 \mathrm{~B}$ exhibited a rising baseline indicating a broad exothermic process initiated at least from $393 \mathrm{~K}\left(120^{\circ} \mathrm{C}\right)$. The exothermic feature ended around $923 \mathrm{~K}\left(650^{\circ} \mathrm{C}\right)$.

For both oxidizing and inert environments runs for $50 \mathrm{Si} \cdot 50 \mathrm{BiF}_{3}$, partially reacted samples were recovered from 473,673 and $973 \mathrm{~K}\left(200,400\right.$ and $\left.700^{\circ} \mathrm{C}\right)$.

To better resolve weak processes occurring in Ar, runs with the powder mass increasing from 5 to 10 and to $23 \mathrm{mg}$ were performed for $50 \mathrm{Si} \cdot 50 \mathrm{BiF}_{3}$. The respective TG traces are presented in Figure 6. The step-like features observed during mass loss were prominent for the lowest sample loading of $5 \mathrm{mg}$, for which a mass gain was also noted around $543 \mathrm{~K}\left(270{ }^{\circ} \mathrm{C}\right)$, which was close to the melting temperature of bismuth (marked in the Figure 6). The mass gain could have been caused by oxidation of the sample reacting with trace oxygen remaining in the furnace despite it being flushed with Ar. Melting of Bi could have accelerated such oxidation. When the sample was heated to a higher temperature of $1473 \mathrm{~K}\left(1200^{\circ} \mathrm{C}\right)$, cf. $23 \mathrm{mg}$ trace, a strong mass loss of $33 \%$ was observed with an onset at $1173 \mathrm{~K}\left(900^{\circ} \mathrm{C}\right)$, which could only be associated with the loss of Bi.

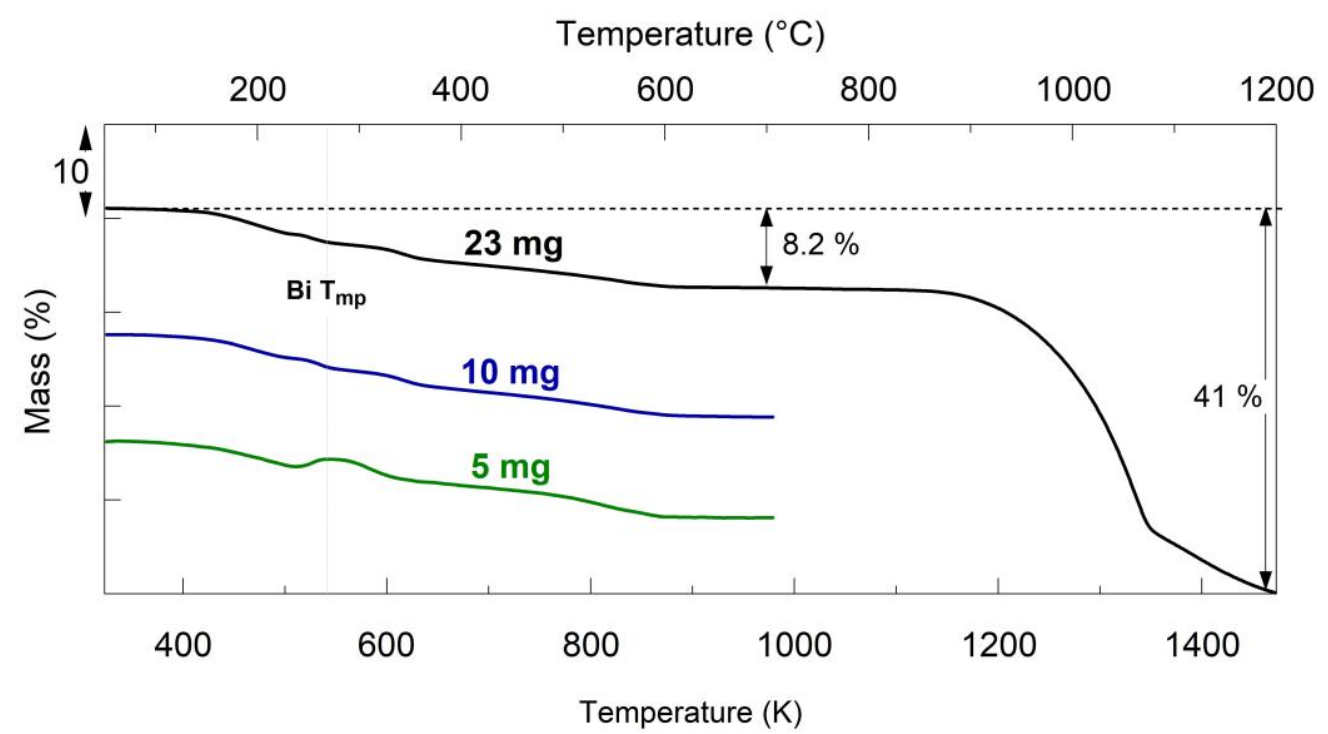

Figure 6. TG traces for different mass samples of $50 \mathrm{Si} \cdot 50 \mathrm{BiF}_{3}$ heated in $\mathrm{Ar}$ at $5 \mathrm{~K} / \mathrm{min}$.

SEM images of partially reacted $50 \mathrm{Si} \cdot 50 \mathrm{BiF}_{3}$ recovered from different temperatures in inert and oxidizing environments are presented in Figure 7. The powder heated to $700{ }^{\circ} \mathrm{C}$ in $\mathrm{Ar}$ (Figure 7A) shows bright spherical bismuth particles studded on darker silicon particles. The dispersion of bismuth across silicon particles was largely preserved. For the sample heated to $700{ }^{\circ} \mathrm{C}$ in $\mathrm{Ar} / \mathrm{O}_{2}$ (Figure $7 \mathrm{~B}$ ), elongated crystals, appearing to be $\mathrm{Bi}_{2} \mathrm{SiO}_{5}$ from EDX analysis, are observed; see the inset for details. Minor bright spheroidal particles rich in Bi were found decorating the surface of the darker Si-rich matrix. EDX shows oxygen present in all phases.

Figure $7 \mathrm{C}$ shows a characteristic particle heated to $1473 \mathrm{~K}\left(1200^{\circ} \mathrm{C}\right)$ in $\mathrm{Ar}$. It is porous and consists of several fused parts. Figure 7D provides a higher magnification image, presenting the surface morphology with multiple small spherical submicron bismuth-rich particles and lamellae of silicon crystal. In materials heated in both $\mathrm{Ar}$ and $\mathrm{Ar} / \mathrm{O}_{2}$, EDX detects iron and chromium; both contaminants came from the steel milling balls. 

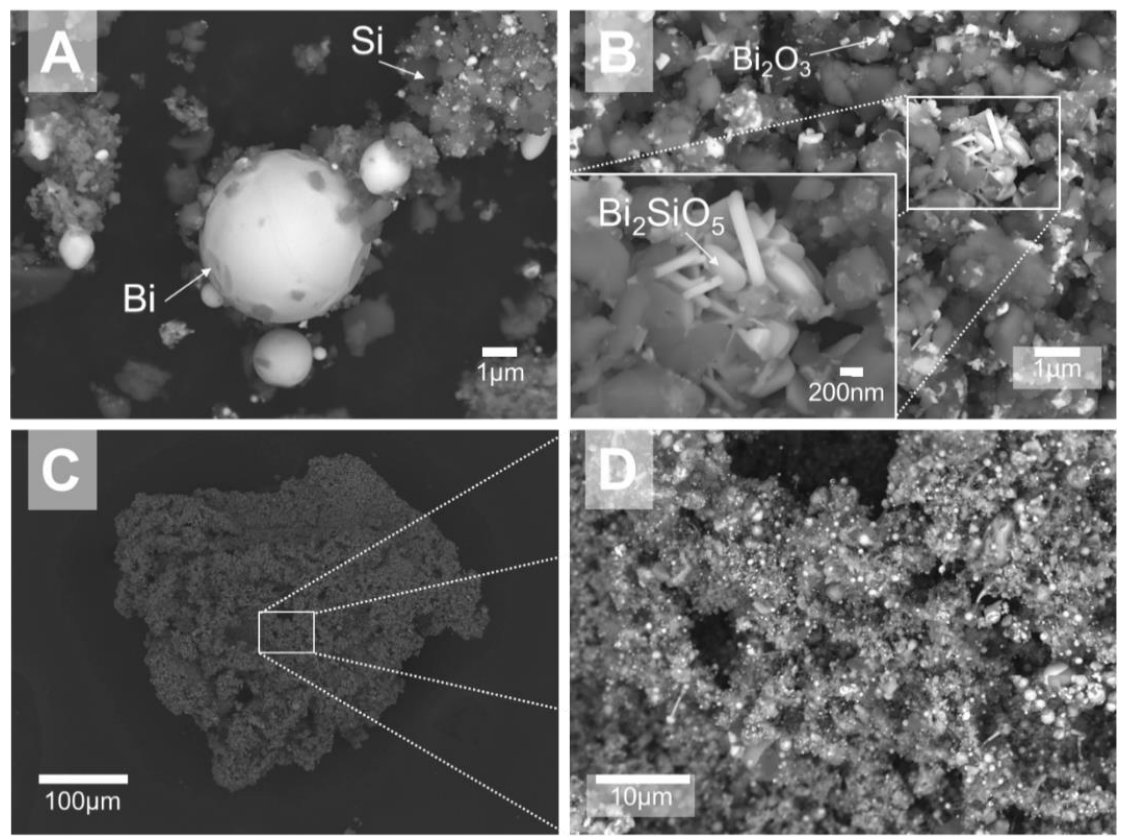

Figure 7. Backscattered electron images of the two-stage milled composite $50 \mathrm{Si} \cdot 50 \mathrm{BiF}_{3}$ heated at $5 \mathrm{~K} / \mathrm{min}$ and recovered from $973 \mathrm{~K}\left(700{ }^{\circ} \mathrm{C}\right)$ : $(\mathbf{A})$ in $\mathrm{Ar}$, $(\mathbf{B})$ in $\mathrm{Ar} / \mathrm{O}_{2}$ and recovered from $1473 \mathrm{~K}\left(1200^{\circ} \mathrm{C}\right)$ in $\operatorname{Ar}(\mathbf{C}, \mathbf{D})$.

XRD patterns for $50 \mathrm{Si} \cdot 50 \mathrm{BiF}_{3}$ and $50 \mathrm{Si} \cdot 50 \mathrm{CoF}_{2}$ heated to different temperatures in Ar and recovered for analysis are presented in Figure 8, along with the reference pattern for the as-milled material. The specific peaks of oxyfluoride $\mathrm{Bi}_{7} \mathrm{~F}_{11} \mathrm{O}_{5}$ in the as milled sample have not been presented in the Figure 8 due to space constraints.
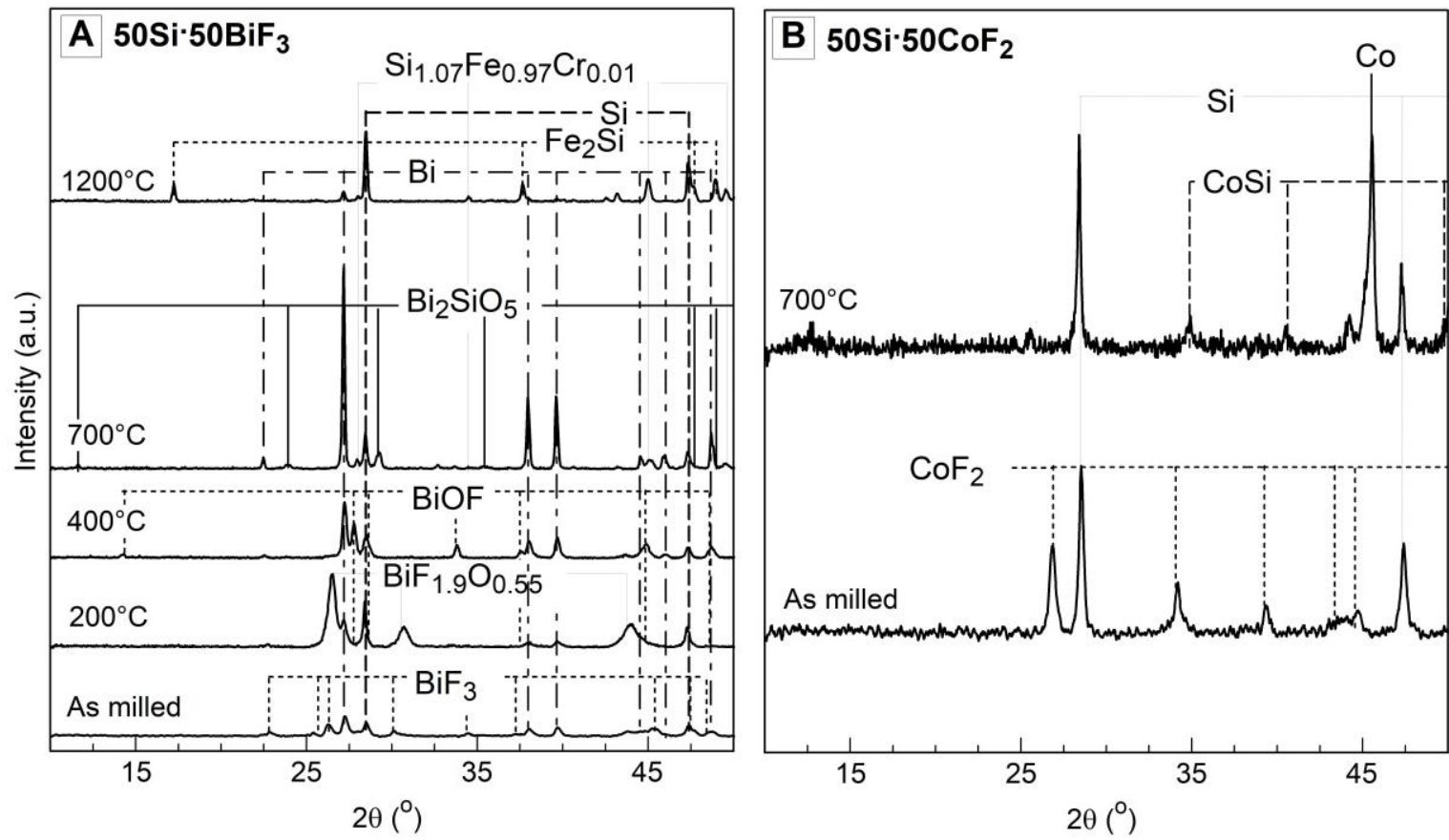

Figure 8. The XRD traces of the two-stage milled composites: (A) $50 \mathrm{Si} \cdot 50 \mathrm{BiF}_{3}$ and (B) $50 \mathrm{Si} \cdot 50 \mathrm{CoF}_{2}$ heated at $5 \mathrm{~K} / \mathrm{min}$ in $\mathrm{Ar}$ and quenched at different temperatures.

Despite Ar purge, traces of oxygen were expected in these runs. For $50 \mathrm{Si} \cdot 50 \mathrm{BiF}_{3}$ (Figure $8 \mathrm{~A}$ ) peaks associated to $\mathrm{BiF}_{3}$ are depressed by $473 \mathrm{~K}\left(200{ }^{\circ} \mathrm{C}\right)$. Simultaneously, $\mathrm{BiF}_{1.9} \mathrm{O}_{0.55}$ peaks [33] became 
dominant and $\mathrm{Bi}_{7} \mathrm{~F}_{11} \mathrm{O}_{5}$ peaks from starting powder disappeared. At $673 \mathrm{~K}\left(400{ }^{\circ} \mathrm{C}\right)$, strong peaks of $\mathrm{Bi}$, $\mathrm{Si}$ and the fluorine containing $\mathrm{BiOF}$ became predominant. By $973 \mathrm{~K}\left(700^{\circ} \mathrm{C}\right)$, peaks corresponding to fluorinated species disappeared, remaining were peaks of $\mathrm{Bi}$ and $\mathrm{Si}$ and minor peaks attributed to $\mathrm{Bi}_{2} \mathrm{SiO}_{5}$ and $\mathrm{Fe}_{2} \mathrm{Si}$. At $1473 \mathrm{~K}\left(120{ }^{\circ} \mathrm{C}\right)$, Bi peaks diminished, and peaks of $\mathrm{Si}$ became stronger. Patterns attributed to iron and chromium impurities, such as $\mathrm{Fe}_{2} \mathrm{Si}$ and $\mathrm{Si}_{1.07} \mathrm{Fe}_{0.97} \mathrm{Cr}_{0.01}$ were also noted.

For $50 \mathrm{Si} \cdot 50 \mathrm{CoF}_{2}$, the $\mathrm{XRD}$ patterns of the starting powder and of the material heated to $700{ }^{\circ} \mathrm{C}$ in Ar are shown in Figure 8B. $\mathrm{CoF}_{2}$ peaks disappeared for the heated material; aside from elemental $\mathrm{Co}$ and $\mathrm{Si}$, a pattern for $\mathrm{CoSi}$ was observed.

XRD patterns for the powders heated to different temperatures in $\mathrm{Ar} / \mathrm{O}_{2}$ for $50 \mathrm{Si} \cdot 50 \mathrm{BiF}_{3}$ and $50 \mathrm{Si} \cdot 50 \mathrm{CoF}_{2}$ are presented in Figure 9. As seen in Figure 9A, the as milled $50 \mathrm{Si} \cdot 50 \mathrm{BiF}_{3}$ had prominent peaks of $\mathrm{BiF}_{3}, \mathrm{Si}, \mathrm{Bi}$ and weaker peaks of $\mathrm{Bi}_{7} \mathrm{~F}_{11} \mathrm{O}_{5}$. The material recovered from $473 \mathrm{~K}\left(200{ }^{\circ} \mathrm{C}\right)$ exhibited weaker $\mathrm{BiF}_{3}$ peaks while $\mathrm{Bi}$ and the oxyfluoride $\mathrm{BiF}_{1.9} \mathrm{O}_{0.55}$ peaks became stronger. By $673 \mathrm{~K}$ $\left(400{ }^{\circ} \mathrm{C}\right)$, the $\mathrm{BiF}_{3}$ peaks were absent, $\mathrm{Si}$ peaks diminished appreciably, while a new oxyfluoride species, BiOF was observed. By $973 \mathrm{~K}\left(700^{\circ} \mathrm{C}\right)$, oxidized products, $\mathrm{Bi}_{2} \mathrm{SiO}_{5}$ and $\mathrm{Bi}_{6} \mathrm{Cr}_{2} \mathrm{O}_{15}$ were the primary species. Minor peaks corresponding to Si were observed as well.
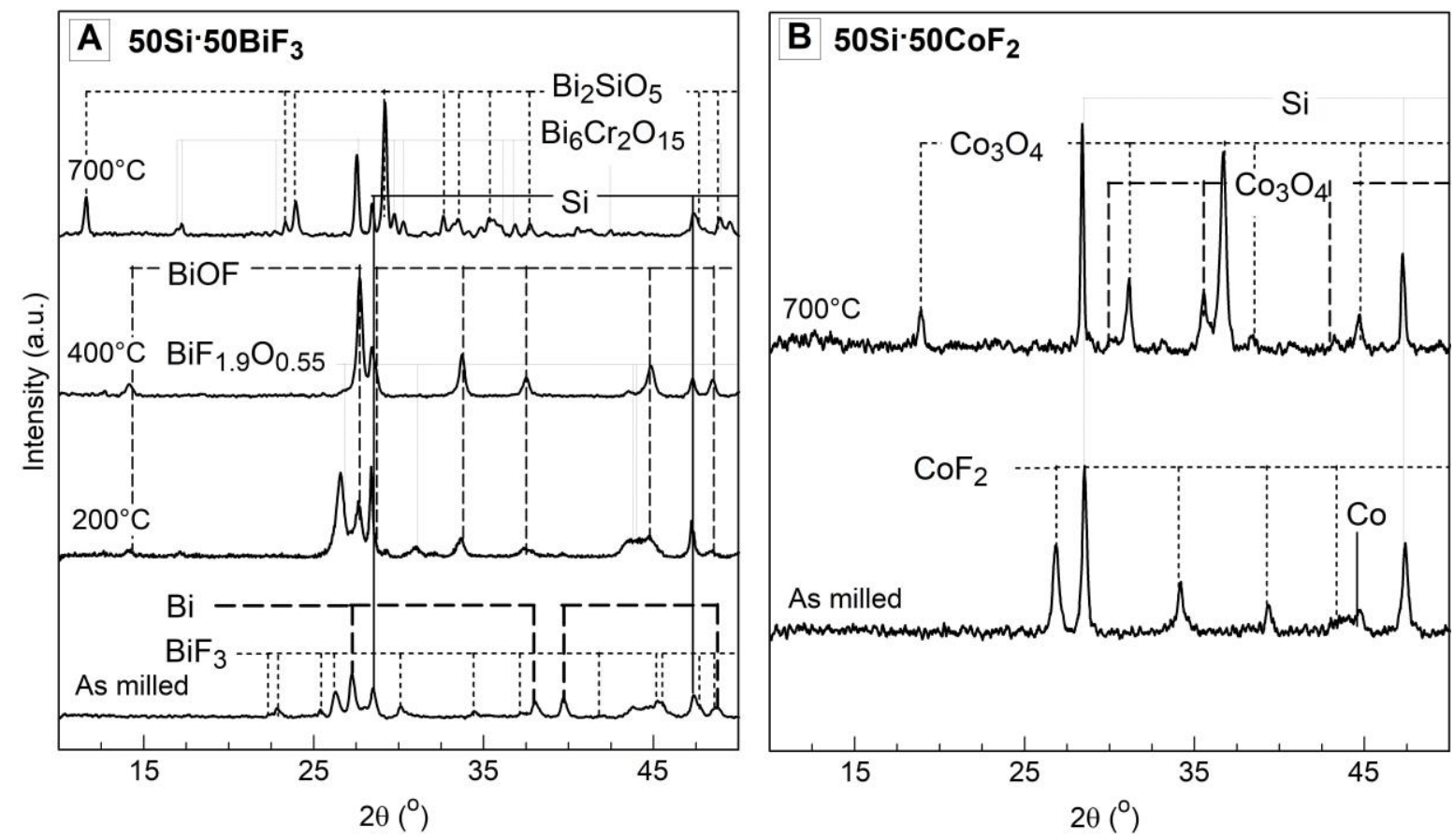

Figure 9. $\mathrm{XRD}$ patterns of the two-stage milled composites (A) $50 \mathrm{Si} \cdot 50 \mathrm{BiF}_{3}$ and (B) $50 \mathrm{Si} \cdot 50 \mathrm{CoF}_{2}$ heated at $5 \mathrm{~K} / \mathrm{min}$ in $\mathrm{Ar} / \mathrm{O}_{2}$ and recovered from different temperatures.

The XRD patterns for as-milled $50 \mathrm{Si} \cdot 50 \mathrm{CoF}_{2}$ and that quenched at $973 \mathrm{~K}\left(70{ }^{\circ} \mathrm{C}\right)$ in $\mathrm{Ar} / \mathrm{O}_{2}$ are presented in Figure 9B. Strong peaks of the oxide of cobalt, $\mathrm{Co}_{3} \mathrm{O}_{4}$ and unreacted $\mathrm{Si}$ were observed.

\subsection{Heated Filament Ignition}

High-speed video frames for all materials igniting on a heated filament are presented in Figure 10. The frames are labeled with the temperature of the filament.

All prepared materials exhibited ignition at low temperatures well before the filament turns incandescent. The incandescence of particles marks the ignition in fuel-rich $50 \mathrm{wt} . \%$ silicon compositions as indicated by arrows in the respective first frames. The 1-stage $50 \mathrm{Si} \cdot 50 \mathrm{BiF}_{3}$ composite exhibited less bright, short-lived particle streaks within an incandescent plume. At higher temperatures (see $857 \mathrm{~K}$ ) a weak secondary ignition event was observed as marked in the frame. 

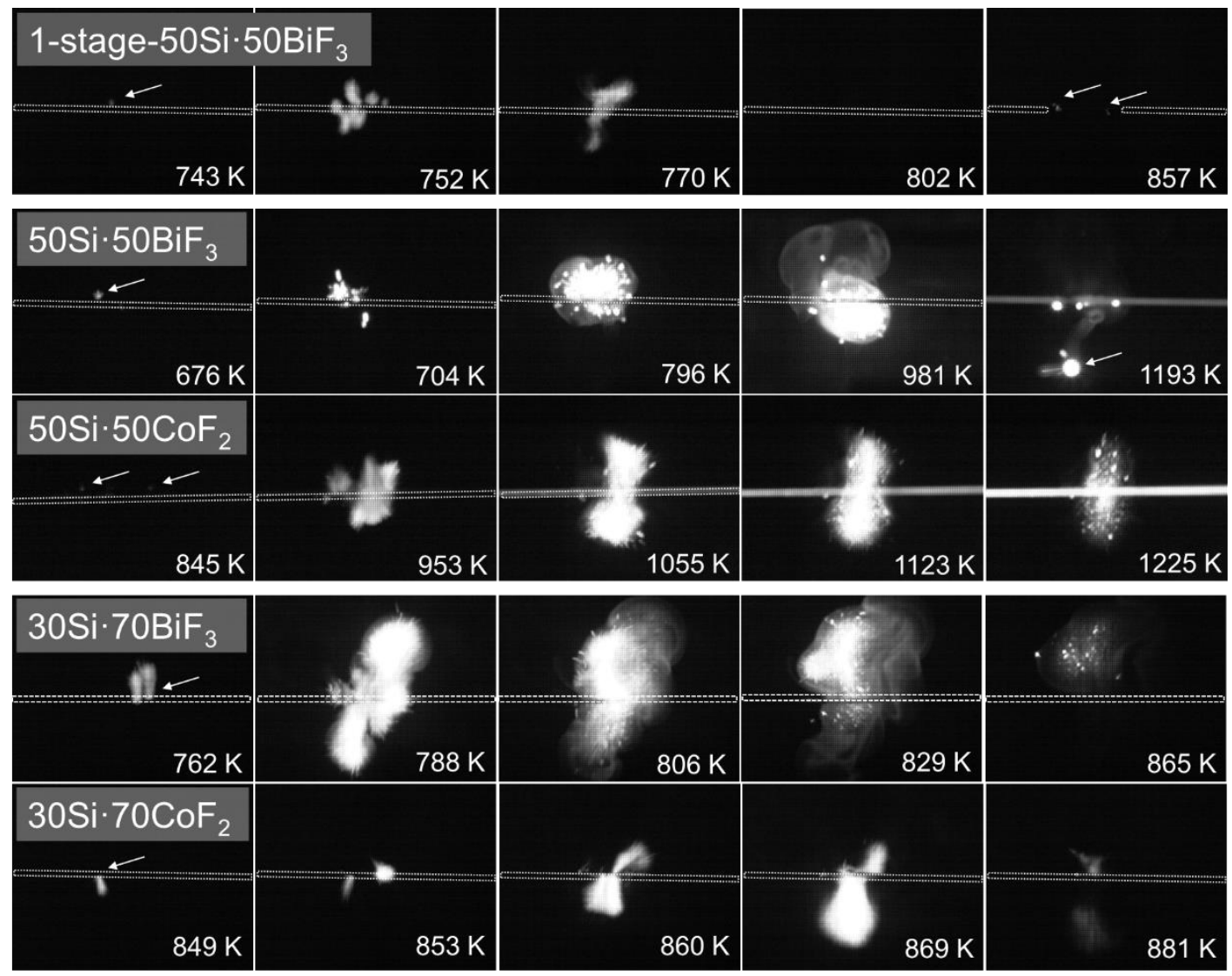

Figure 10. High-speed video frames of the ignition of 1 -stage $50 \mathrm{Si} \cdot 50 \mathrm{BiF}_{3}$ (heated at $2100 \mathrm{~K} / \mathrm{s}$ ) and two-stage milled materials; $50 \mathrm{Si} \cdot 50 \mathrm{BiF}_{3}$ (heated at $3800 \mathrm{~K} / \mathrm{s}$ ), $50 \mathrm{Si} \cdot 50 \mathrm{CoF}_{2}$ (heated at $2100 \mathrm{~K} / \mathrm{s}$ ), $30 \mathrm{Si} \cdot 70 \mathrm{BiF}_{3}$ (heated at $2200 \mathrm{~K} / \mathrm{s}$ ) and $30 \mathrm{Si} \cdot 70 \mathrm{CoF}_{2}$ (heated at $2200 \mathrm{~K} / \mathrm{s}$ ), on an electrically heated nichrome wire. The wire temperatures are indicated.

For $50 \mathrm{Si} \cdot 50 \mathrm{BiF}_{3}$, bright smoke enveloped the burning particles flying off the filament, as seen in frames captured above $796 \mathrm{~K}$. The $50 \mathrm{Si} \cdot 50 \mathrm{CoF}_{2}$ material ignited producing a bright plume with few particle streaks, which became prominent at higher wire temperatures (>1123 K).

For materials with higher fluoride content, $30 \mathrm{Si} \cdot 70 \mathrm{BiF}_{3}$ and $30 \mathrm{Si} \cdot 70 \mathrm{CoF}_{2}$, ignition caused luminescent plume flares. For $30 \mathrm{Si} \cdot 70 \mathrm{BiF}_{3}$, particle streaks and smoke were observable above $806 \mathrm{~K}$. The $30 \mathrm{Si} \cdot 70 \mathrm{CoF}_{2}$ composite generated a bright plume and no detectable burning particles.

The measured ignition temperatures of all prepared materials are shown as a function of heating rates in Figure 11. The error bars represent the scatter in 5 runs performed for each targeted heating rate. All ignition temperatures increase with the heating rate.

Lower ignition temperatures were measured for the materials with $\mathrm{BiF}_{3}$ compared to those with $\mathrm{CoF}_{2}$. The composites with $50 \mathrm{wt} . \% \mathrm{Si}$ ignited consistently at lower temperatures compared to the composites with $30 \mathrm{wt} . \% \mathrm{Si}$. The 1-stage $50 \mathrm{Si} \cdot 50 \mathrm{BiF}_{3}$ had a higher ignition temperature comparable to its two-stage milled analog, $50 \mathrm{Si} \cdot 50 \mathrm{BiF}_{3}$. The secondary ignition for 1-stage $50 \mathrm{Si} \cdot 50 \mathrm{BiF}_{3}$ could only be clearly detected at lower heating rates. At higher heating rates, this secondary ignition could have occurred at much higher temperatures and was not discernable due to the bright filament emission. 


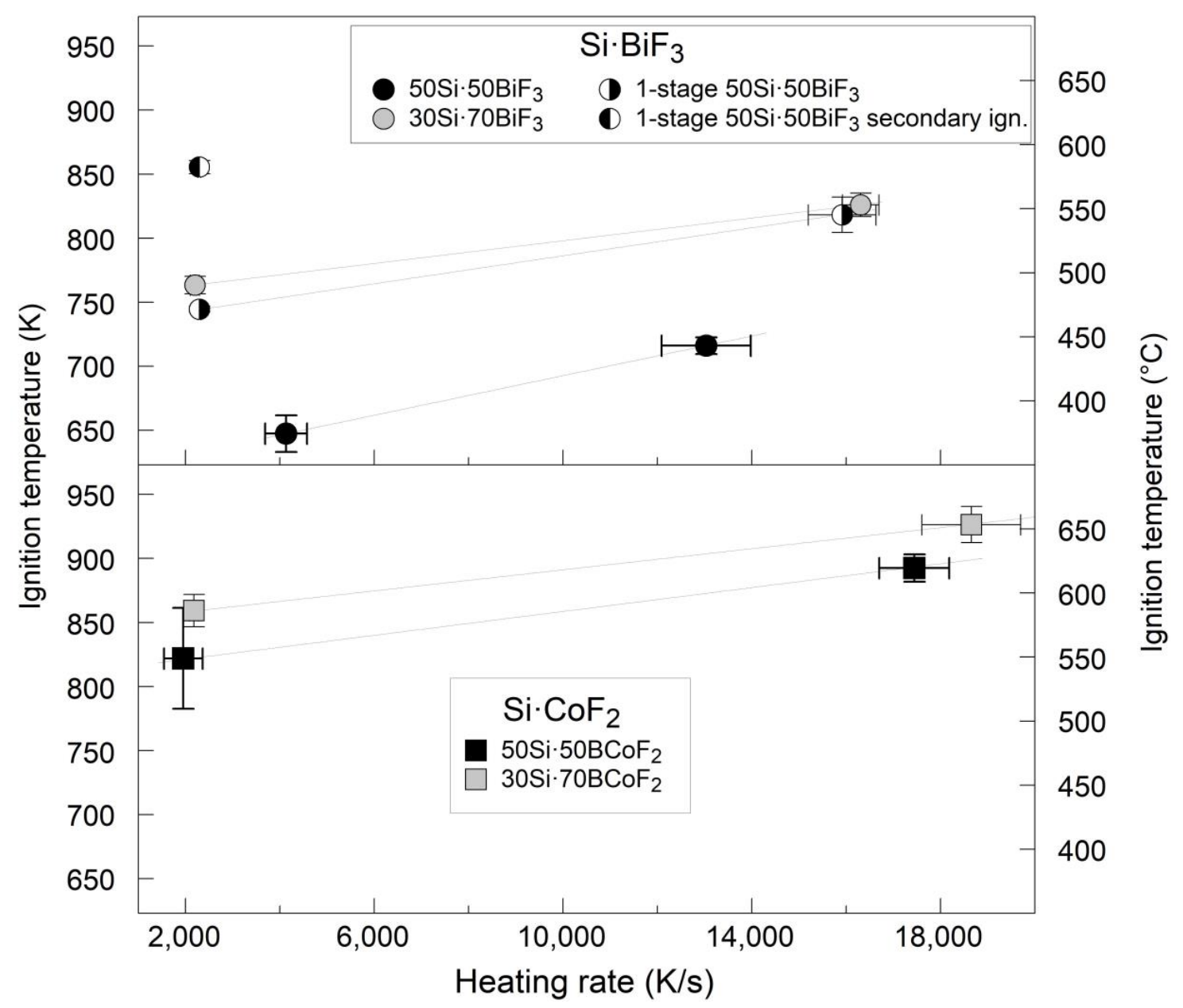

Figure 11. Ignition temperature in air of all prepared materials as a function of the heating rate.

\subsection{Particle Combustion}

In experiments employing the laser ignition of composite particles, $50 \mathrm{Si} \cdot 50 \mathrm{CoF}_{2}$ powder could not be fed consistently. Conversely, $50 \mathrm{Si} \cdot 50 \mathrm{BiF}_{3}$ powder was easy to feed; thus, only the experimental results with this powder are presented. Attempts to ignite milled Si powder, which could be fed into the laser beam, were not successful. Additionally, condensed combustion products could not be collected for analysis, likely because of the substantial amounts of gaseous combustion products.

A representative emission pulse of a laser-ignited $50 \mathrm{Si} \cdot 50 \mathrm{BiF}_{3}$ particle burning in air is shown in Figure 12. All pulses observed had single peaks with minor oscillatory features. A distribution of the particle burn times is shown in Figure 13. It peaked at $0.43 \mathrm{~ms}$ with a tail trailing towards longer times. 


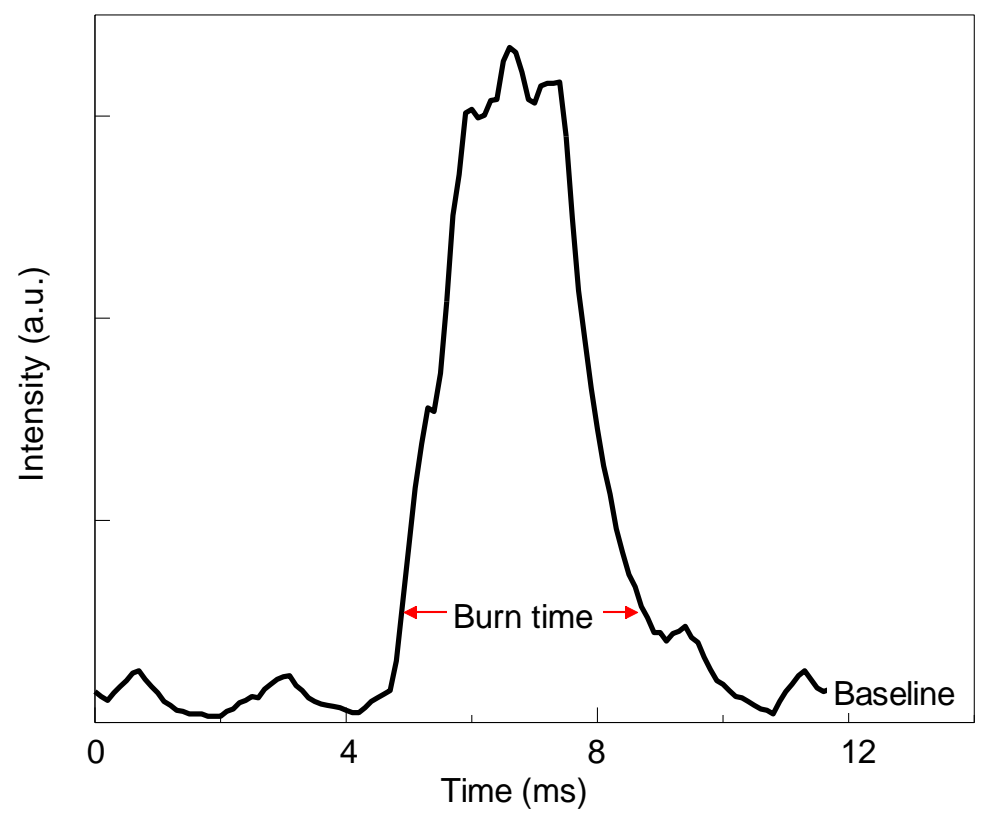

Figure 12. A representative emission pulse produced by a $50 \mathrm{Si} \cdot 50 \mathrm{BiF}_{3}$ particle burning in air.

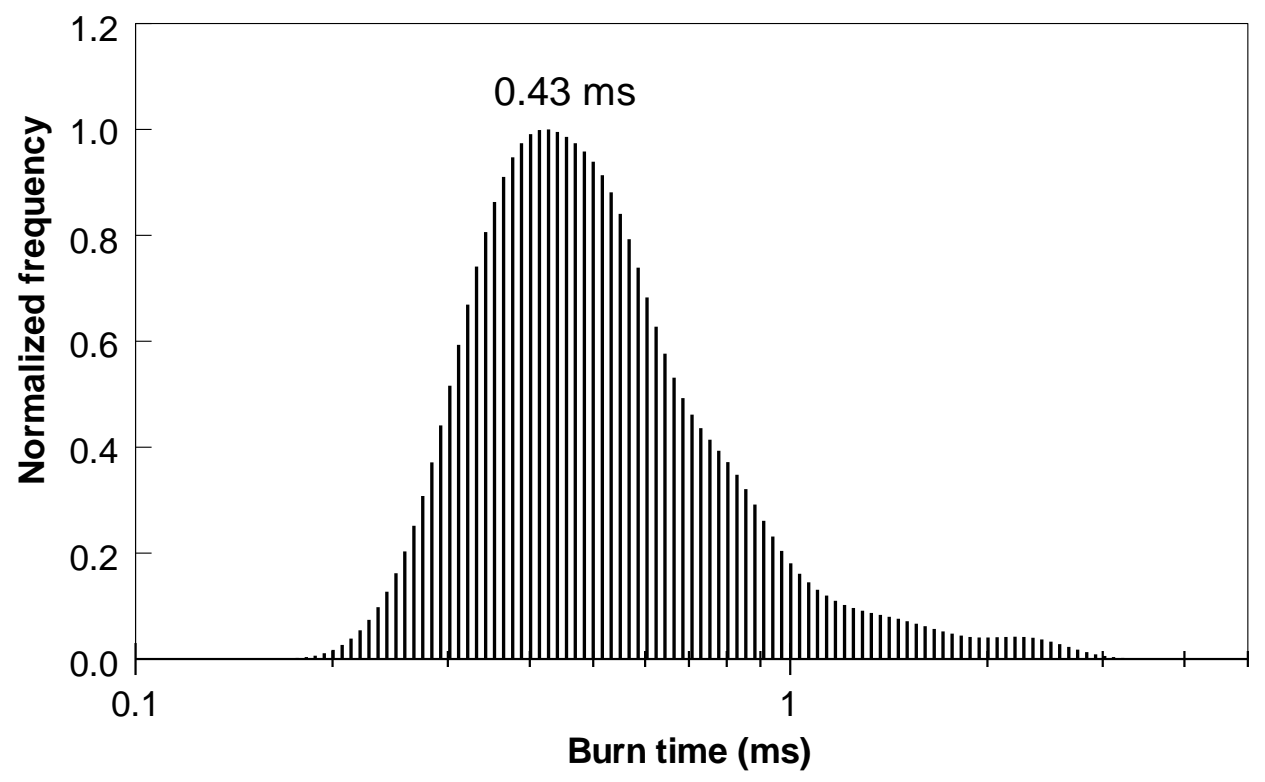

Figure 13. The burn time distribution for particles of $50 \mathrm{Si} \cdot 50 \mathrm{BiF}_{3}$ burning in air.

The size distribution of the aerosolized $50 \mathrm{Si} \cdot 50 \mathrm{BiF}_{3}$ particles passed through the feeder is shown in Figure 14. The distribution was nearly symmetrical, with a mode of $3.09 \mu \mathrm{m}$. 


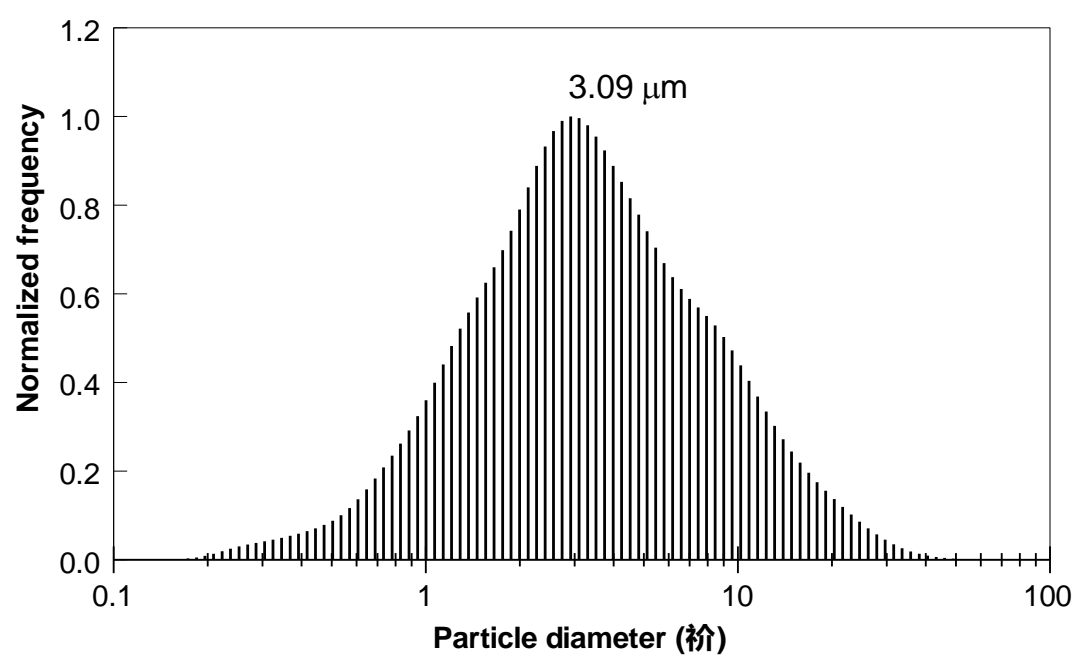

Figure 14. The particle size distribution for aerosolized $50 \mathrm{Si} \cdot 50 \mathrm{BiF}_{3}$ powder passed through the feeder.

The burn time distribution was correlated with the particle size distribution for $50 \mathrm{Si} \cdot 50 \mathrm{BiF}_{3}$; the correlation plot is presented in Figure 15 along with earlier results for other metal-metal fluoride composites obtained using the same data processing method [20,23]. Like $\mathrm{Al}$ and B-based composites using $\mathrm{BiF}_{3}$ as an oxidizer, $50 \mathrm{Si} \cdot 50 \mathrm{BiF}_{3}$ composite powder particles burn rapidly, with most burn times under $1 \mathrm{~ms}$. These times were shorter than reported burn times for $\mathrm{Al}$ particles of the same sizes.

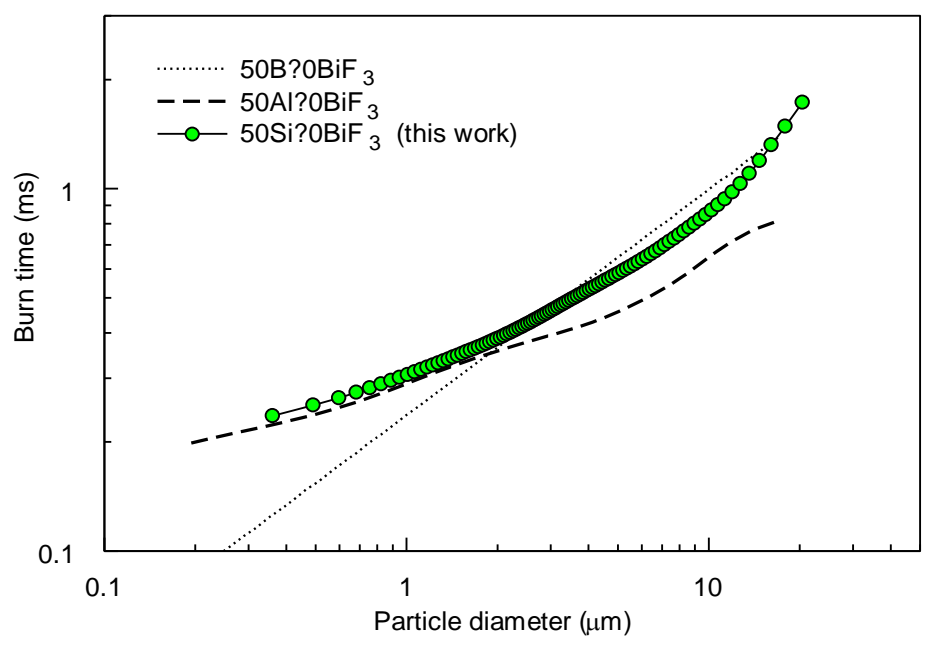

Figure 15. Burn time-particle size correlation for $50 \mathrm{Si} \cdot 50 \mathrm{BiF}_{3}$ powder ignited in air by a laser. For comparison, similar correlations are shown for powders of $50 \mathrm{Al} \cdot 50 \mathrm{BiF}_{3}[20]$ and $50 \mathrm{~B} \cdot 50 \mathrm{BiF}_{3}[23$ ] obtained by arrested reactive milling.

The adiabatic flame temperature and predicted mole fractions of the combustion products of $50 \mathrm{Si} \cdot 50 \mathrm{CoF}_{2}$ burning in air calculated by NASA CEA code [34] are presented in the Supplementary Section Figure S1. The particle surface temperature during combustion is expected to be close to $2750 \mathrm{~K}$ (predicted to be the adiabatic flame temperature), sufficiently high for gasifying a significant fraction of the main combustion product $\mathrm{SiO}_{2}$. 


\section{Discussion}

\subsection{Material Preparation}

A single-stage milling protocol does not effectively mix the physically different fluoride and silicon powders. Conversely, using premilled silicon for the second step milling with metal fluorides yields well-homogenized nanocomposite powders.

Materials with $\mathrm{CoF}_{2}$ have distinct morphological features, where the fluoride formed a coating on the larger silicon particles. Even with increased fluoride content, no loose fluoride or uncoated silicon particles were observed in $30 \mathrm{Si} \cdot 70 \mathrm{CoF}_{2}$. It is surprising that such a fine scale of mixing was achieved without detectable mechanochemical reaction, e.g., lack of reduced Co detected by XRD of as-milled powders (see Figure 3). The XRD results were consistent with the thermal analysis, Figure $4 \mathrm{~A}$. The complete reduction of $\mathrm{CoF}_{2}$ by silicon to form gaseous $\mathrm{SiF}_{4}$ resulted in a mass loss of $26 \%$. This was close to the mass loss of $23 \mathrm{wt}$. \% measured by TG.

Based on $\mathrm{XRD}$ of the as-milled $50 \mathrm{Si} \cdot 50 \mathrm{BiF}_{3}$ showing the presence of reduced bismuth and bismuth oxyfluorides, it was estimated that $\mathrm{BiF}_{3}$ made up only $28.5-30 \mathrm{wt} \%$, with the remaining 20-21.5 wt. $\%$ of $\mathrm{BiF}_{3}$ lost before or during milling. Accounting for this initial amount of $\mathrm{BiF}_{3}$ available in the as-milled powder, it is expected that the complete reaction of $\mathrm{Si}$ with the remaining $\mathrm{F}$ in the material would result in an observable mass loss of close to $8.9 \%$. This agreed reasonably with the mass loss of $8.3 \%$ observed in TG (Figure 7A). While a smaller fraction of the fluoride reacted and was lost for the 1-stage $50 \mathrm{Si} \cdot 50 \mathrm{BiF}_{3}$, the mixing scale and homogeneity for that composite material were inadequate.

\subsection{Low-Temperature Reactions}

The TG for $50 \mathrm{Si} \cdot 50 \mathrm{BiF}_{3}$ and $50 \mathrm{Si} \cdot 50 \mathrm{CoF}_{2}$ in Ar shows a mass loss due to the evolution of $\mathrm{SiF}_{4}$, described by reaction (1). As seen in Figure $4, \mathrm{SiF}_{4}$ formation in $50 \mathrm{Si} \cdot 50 \mathrm{CoF}_{2}$ occurred in a single step between 661 and $873 \mathrm{~K}\left(388\right.$ and $\left.600^{\circ} \mathrm{C}\right)$. Conversely, for $50 \mathrm{Si} \cdot 50 \mathrm{BiF}_{3}$, the mass decreased gradually, with discernable stages starting from ca. $423 \mathrm{~K}\left(150^{\circ} \mathrm{C}\right)$ and extending to $873 \mathrm{~K}\left(600^{\circ} \mathrm{C}\right)$.

In $\mathrm{Ar} / \mathrm{O}_{2}$ oxidation of the reduced metal and oxidation of silicon occur parallel to fluorination of silicon. Both oxide formation reactions form condensed products and thus increase the mass. Assuming for simplicity that the fluorination occurs similarly in both $\mathrm{Ar}$ and $\mathrm{Ar} / \mathrm{O}_{2}$ environments, the mass gain due to oxidation, $\Delta m_{0 x}$, can be estimated from the mass difference between measurements in $\mathrm{Ar} / \mathrm{O}_{2}$ and in Ar:

$$
\Delta m_{o x}=\Delta m_{A r / O_{2}}-\Delta m_{A r}
$$

This change of mass is shown in Figure 16. The mass gain due to oxidation consists of two components, caused by oxidation of silicon, $\Delta m_{o x}^{S i}$ and that of the reduced metal, $\Delta m_{o x}^{M e}$. The value of $\Delta m_{o x}^{M e}$ can be estimated from the mass measured in Ar, assuming $\Delta m_{A r}$ is entirely due to evolution of $\mathrm{SiF}_{4}$ and assuming that all the reduced metal oxidizes immediately when the reaction occurs in $\mathrm{Ar} / \mathrm{O}_{2}$ :

$$
\Delta m_{o x}^{M e}=\Delta m_{A r}^{M e}=\frac{M_{M e}}{M_{S i F_{4}}} \cdot \frac{x}{4} \Delta m_{A r}
$$

Subtracting this mass from $\Delta m_{0 x}$ gives:

$$
\Delta m_{o x}^{S i}=\Delta m_{o x}-\Delta m_{o x}^{M e}
$$

Finally, the rate of Si oxidation can be obtained dividing the derivative $d\left(\Delta m_{o x}^{S i}\right) / d t$ by the mass of Si remaining in the material accounting for $\mathrm{SiF}_{4}$ leaving as gas (Equation (1)), also based on the TG measured in Ar. 


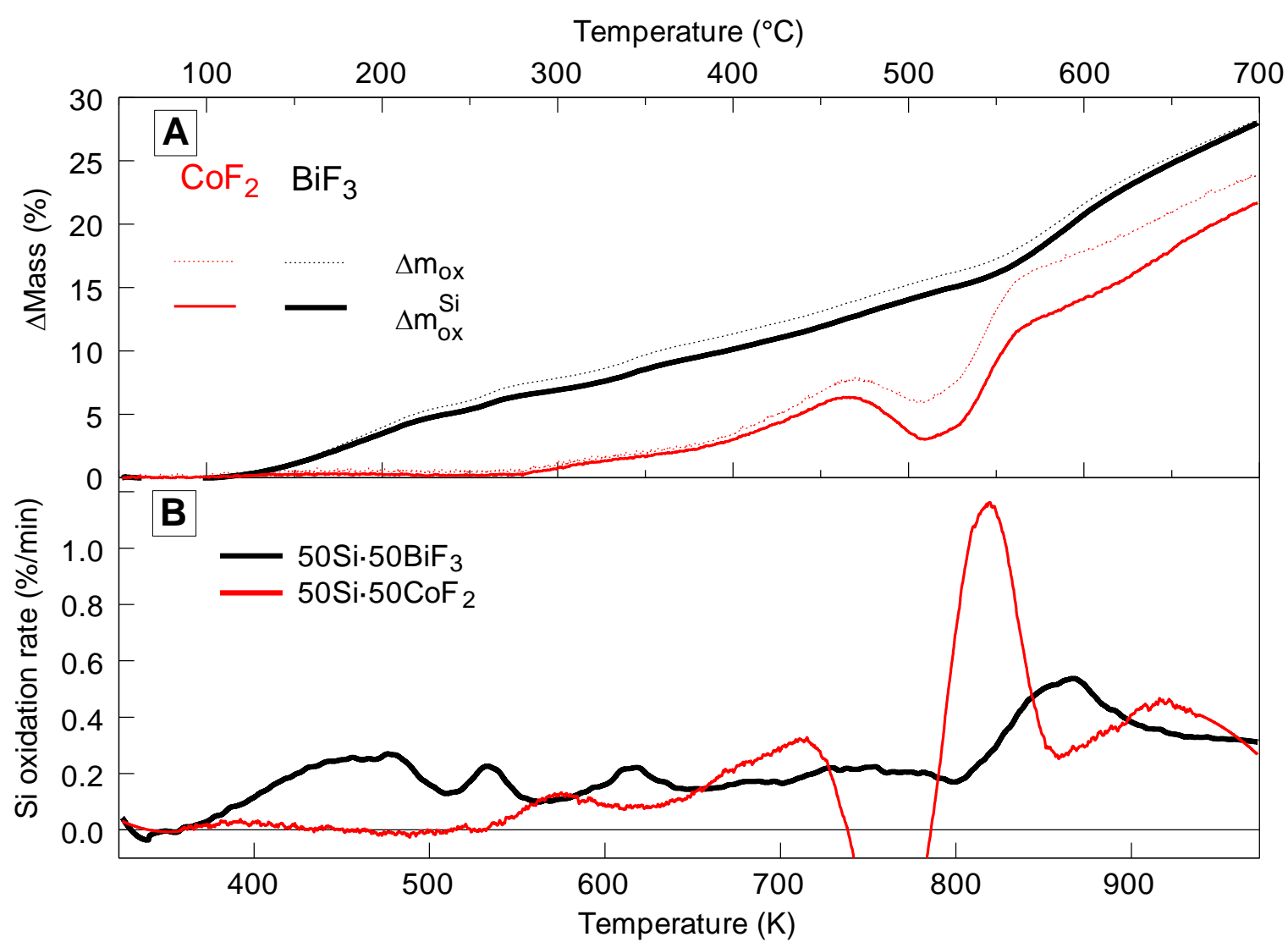

Figure 16. The (A) oxidative mass gain and corresponding (B) silicon oxidation rate of two-stage milled materials $50 \mathrm{Si} \cdot 50 \mathrm{BiF}_{3}$ and $50 \mathrm{Si} \cdot 50 \mathrm{CoF}_{2}$.

Processing experimental traces using Equations (2) and (4) yields traces for $\Delta m_{o x}, \Delta m_{o x}^{S i}$, and the rate, $\frac{1}{m_{S i}} \frac{d\left(\Delta m_{o x}^{S i}\right)}{d t}$ shown in Figure 16. Figure 16B shows that the rate of silicon oxidation parallels the observed rate of oxidation in the $\mathrm{Ar} / \mathrm{O}_{2}$ environment. Since only as much Me oxide can form as $\mathrm{MeF}_{\mathrm{x}}$ has been reduced, the bulk of the observed mass gain represents the oxidation of Si. The apparent negative $\mathrm{Si}$ oxidation rate seen for $50 \mathrm{Si} \cdot 50 \mathrm{CoF}_{2}$ at between 450 and $500{ }^{\circ} \mathrm{C}$ suggests that the assumption that $\mathrm{SiF}_{4}$ formation is identical in $\mathrm{Ar}$ and $\mathrm{Ar} / \mathrm{O}_{2}$ environments is not strictly true.

For $50 \mathrm{Si} \cdot 50 \mathrm{CoF}_{2}$, Figure 16 suggests that oxidation of $\mathrm{Si}$ began at a higher temperature than the corresponding $\mathrm{SiF}_{4}$ formation (cf. Figure 4); it also began at a higher temperature than for $50 \mathrm{Si}^{-} 50 \mathrm{BiF}_{3}$, for which oxidation began simultaneously with fluorination (cf. Figure 5). For both composites, the oxidation rate of $\mathrm{Si}$ increased initially and then became relatively stable over a range of temperatures. For both composites the low-temperature rates of heat release associated with the observed initial rate of oxidation of $\mathrm{Si}$ could be added to the rates of heat release caused by the Si fluorination occurring simultaneously (e.g., recovered from data in Figures 4 and 5 for $50 \mathrm{Si} \cdot 50 \mathrm{CoF}_{2}$ and $50 \mathrm{Si} \cdot 50 \mathrm{BiF}_{3}$, respectively) to describe the exothermic reactions leading to ignition of such composite materials.

Aside of relatively small changes in the reaction rate for $50 \mathrm{Si} \cdot 50 \mathrm{BiF}_{3}$, a stepwise increase in the oxidation rate is observed between 803 and $973 \mathrm{~K}\left(530\right.$ and $\left.600^{\circ} \mathrm{C}\right)$. As discussed below, this accelerated oxidation at relatively high temperatures was unlikely to affect ignition of the prepared composite. For $50 \mathrm{Si} \cdot 50 \mathrm{CoF}_{2}$ the apparent oxidation rate of Si dropped around $723 \mathrm{~K}\left(450^{\circ} \mathrm{C}\right)$. However, based on Figure 5, it can be concluded that this effect was superficial and simply means that the fluorination of $\mathrm{Si}$ accelerated rapidly at such temperatures, with the associated mass loss becoming stronger than mass gain due to oxidation of both $\mathrm{Si}$ and reduced $\mathrm{Co}$. Indeed, after a while, the oxidation rate of $\mathrm{Si}$ returned to about the same level it was at just below $723 \mathrm{~K}$. 


\subsection{Reactions Leading to Ignition}

The onsets of TG features observed in both inert and oxidizing environment runs for both $50 \mathrm{Si} \cdot 50 \mathrm{BiF}_{3}$ and $50 \mathrm{Si} \cdot 50 \mathrm{CoF}_{2}$ were plotted along with their respective heated filament ignition temperatures in the Kissinger plot shown in Figure 17. The onsets of the mass loss observed in Ar and mass gain in $\mathrm{Ar} / \mathrm{O}_{2}$ for $50 \mathrm{Si} \cdot 50 \mathrm{BiF}_{3}$ nearly coincided with each other for different heating rates. Extrapolating the kinetic trend from the ignition data points down to the range of low heating rates used in thermal analysis pointed clearly to the onsets of the observed mass gain (in $\mathrm{Ar} / \mathrm{O}_{2}$ ) and loss (in $\mathrm{Ar}$ ) as reactions associated with ignition. As discussed above, for $50 \mathrm{Si} \cdot 50 \mathrm{BiF}_{3}$, both fluorination and oxidation of Si occurred nearly simultaneously with both exothermic reactions contributing to igniting the material.

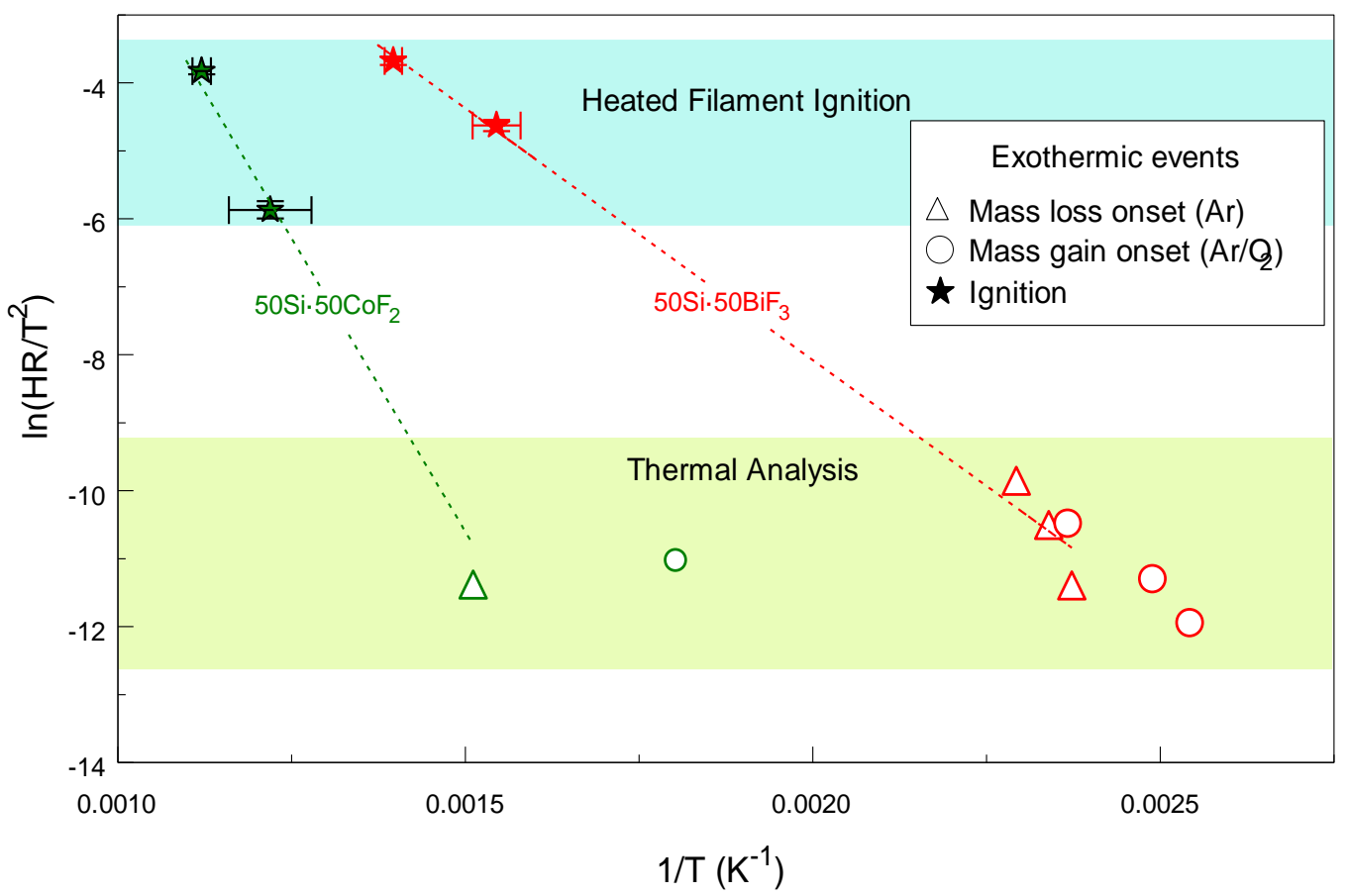

Figure 17. Kissinger plot combining TG and DTA features and heated filament ignition data for two-stage milled $50 \mathrm{Si} \cdot 50 \mathrm{BiF}_{3}$ and $50 \mathrm{Si} \cdot 50 \mathrm{CoF}_{2}$.

The onset of mass loss observed in Ar for $50 \mathrm{Si} \cdot 50 \mathrm{CoF}_{2}$ (for which the measurement was only made at one heating rate) was shifted from that of the mass gain observed for this material heated in $\mathrm{Ar} / \mathrm{O}_{2}$ at a lower temperature. The kinetic trend implied by the respective ignition temperatures lined up better with the mass loss observed in Ar, and thus it was likely that the ignition was mostly associated with $\mathrm{SiF}_{4}$ formation for this composite. It is nonetheless expected that the low-temperature oxidation of $\mathrm{Si}$, once started, assisted ignition. The apparent activation energy that can describe ignition was roughly evaluated from the slopes of line fits shown in Figure 17. These activation energies were around 62 and $140 \mathrm{~kJ} / \mathrm{mol}$ for $50 \mathrm{Si} \cdot 50 \mathrm{BiF}_{3}$ and $50 \mathrm{Si} \cdot 50 \mathrm{CoF}_{2}$, respectively. For $50 \mathrm{Si} \cdot 50 \mathrm{BiF}_{3}$, the inferred activation energy was comparable to that reported for fluorination of silicon wafers by elemental fluorine at reduced fluorine partial pressures [35].

The higher temperature reactions are not shown but would be shifted far left in Figure 17 and thus would be clearly irrelevant for ignition.

\subsection{Particle Combustion}

The micron-sized silicon particles could not be initiated in the laser-assisted combustion experiment. Conversely, the prepared $50 \mathrm{Si} \cdot 50 \mathrm{BiF}_{3}$ composite could be readily initiated and burned in the time frame comparable to other reactive metal-fluoride composite powders. Most likely, initial fluorination of Si 
made it easier to initiate the reaction; however, it is expected that the laser energy was sufficient to rapidly heat Si particles, which did not sustain combustion once exposed to the room temperature air. It is thus suggested that the presence of reduced or partially reduced Bi accelerates both lowand high-temperature heterogeneous oxidation of $\mathrm{Si}$, assisting in establishing and sustaining the particle flame.

As estimated by the CEA code (Figure S1), the high adiabatic flame temperatures volatilize a significant mass fraction of refractory silicon oxides formed during combustion of $50 \mathrm{Si} \cdot 50 \mathrm{CoF}_{2}$. In the case of $50 \mathrm{Si} \cdot 50 \mathrm{BiF}_{3}$, the mass fraction of volatile species might be higher because both bismuth and bismuth oxide vaporize easily. However, once bismuth is oxidized in the presence of a more reactive metal fuel, it is likely to be immediately reduced, serving as an oxygen shuttle. Thus, presence of Bi can effectively accelerate oxidation of $\mathrm{Si}$, similarly to how it was suggested to accelerate oxidation of $\mathrm{Al}$ [20] and $\mathrm{B}$ [23]. When $\mathrm{BiF}_{3}$ serves as an oxidizer with different fuels, including $\mathrm{Al}, \mathrm{B}$ and $\mathrm{Si}$, gas phase products (including fluorides and oxyfluorides of the respective fuels) are favored a the high combustion temperatures. At the same time, the surface reaction may be governed by oxidation of Bi. Respectively, similar rates of combustion, with heterogeneous surface reactions yielding volatile products, are expected for all such composite materials. The rate of such reactions is expected to be controlled by diffusion of the oxidizer (oxygen) to the particle surface in all cases. This reasoning can explain comparable burn times observed for different composites, $50 \mathrm{Al} \cdot 50 \mathrm{BiF}, 50 \mathrm{~B} \cdot 50 \mathrm{BiF} \mathrm{F}_{3}$ and $50 \mathrm{Si} \cdot 50 \mathrm{BiF}_{3}$ for similarly sized particles (Figure 15)

\section{Conclusions}

Preparing Si-based composites with $\mathrm{BiF}_{3}$ and $\mathrm{CoF}_{2}$ as oxidizers required a premilling step to refine the starting commercial Si powder in order to achieve nanoscale mixing between the material components. Preparation of well homogenized composites of $\mathrm{Si}$ with $\mathrm{BiF}_{3}$ could not be achieved without partial reaction of $\mathrm{BiF}_{3}$; however, no such reaction of $\mathrm{CoF}_{2}$ was observed. Upon heating, oxidation of Si occurs at lower temperatures than its fluorination when the added oxidizer is $\mathrm{CoF}_{2}$. Conversely, both oxidation and fluorination occurred nearly simultaneously and at a lower temperature with $\mathrm{BiF}_{3}$ as an oxidizer. The presence of reduced $\mathrm{Co}$ and $\mathrm{Bi}$ accelerated oxidation of Si upon its heating in an oxygen-containing environment.

Unlike elemental $\mathrm{Si}$, prepared composite powders ignited readily when placed as a coating on an electrically heated filament. Ignition of the composite with $\mathrm{BiF}_{3}$ as an oxidizer occurred at consistently lower temperatures than that of the composite with $\mathrm{CoF}_{2}$. Results suggest that low-temperature fluorination and oxidation caused ignition for the composites with $\mathrm{BiF}_{3}$ as an oxidizer; apparent activation energy for reactions leading to ignition was close to $62 \mathrm{~kJ} / \mathrm{mol}$. For the composites with $\mathrm{CoF}_{2}$ as an oxidizer, it is likely that ignition is associated with Si fluorination.

Prepared composite powder with the $\mathrm{BiF}_{3}$ oxidizer ignited readily when passed through a $\mathrm{CO}_{2}$ laser beam in room temperature air. The measured particle burn times were nearly the same as those of similar composites combining $\mathrm{BiF}_{3}$ with such fuels as $\mathrm{Al}$ and $\mathrm{B}$. Combustion products were mostly gaseous making it impossible to collect and analyze produced condensed species.

Supplementary Materials: The following are available online at http://www.mdpi.com/2079-4991/10/12/2367/s1, Figure S1: The calculated adiabatic flame temperature and the combustion products presented as mole fractions at a range of equivalence ratios for $50 \mathrm{Si} \cdot 50 \mathrm{CoF} 2$.

Author Contributions: S.K.V. performed interpreted experiments, prepared first draft of the manuscript; M.S. discussed experimental results and correlated material properties with the reactions observed; E.D. set objectives of the effort, analyzed results, and edited the manuscript. All authors have read and agreed to the published version of the manuscript.

Funding: This research was funded in parts by the Office of Naval Research, Grant N00014-19-1-2048 and by the Defense Threat Reduction Agency, Grant HDTRA1-17-1-0044.

Conflicts of Interest: The authors declare no conflict of interest. 


\section{References}

1. Koch, E.; Clément, D. Special Materials in Pyrotechnics: VI. Silicon-An Old Fuel with New Perspectives. Propellants Explos. Pyrotech. 2007, 32, 205-212. [CrossRef]

2. Yaroshevsky, A.A. Abundances of chemical elements in the Earth's crust. Geochem. Int. 2006, 44, 48-55. [CrossRef]

3. Gelain, C.; Cassuto, A.; Le Goff, P. Kinetics and mechanism of low-pressure, high-temperature oxidation of silicon-II. Oxid. Met. 1971, 3, 139-151. [CrossRef]

4. Rugunanan, R.A.; Brown, M.E. Reactions of powdered silicon with some pyrotechnic oxidants. J. Therm. Anal. Calorim. 1991, 37, 1193-1211. [CrossRef]

5. Deal, B.E.; Grove, A.S. General Relationship for the Thermal Oxidation of Silicon. J. Appl. Phys. 1965, 36, 3770-3778. [CrossRef]

6. Cabrera, N.; Mott, N.F. Theory of the oxidation of metals. Rep. Prog. Phys. 1949, 12, 163-184. [CrossRef]

7. Braun, G.; Boden, G.; Henkel, K.; Rossbach, H. Thermal analysis of the direct nitridation of silicon to Si3N4. J. Therm. Anal. Calorim. 1988, 33, 479-485. [CrossRef]

8. Rugunanan, R.A.; Brown, M.E. Combustion of Binary and Ternary Silicon/Oxidant Pyrotechnic Systems, Part I: Binary Systems with $\mathrm{Fe}_{2} \mathrm{O}_{3}$ and $\mathrm{SnO}_{2}$ as Oxidants. Combust. Sci. Technol. 1993, 95, 61-83. [CrossRef]

9. Mason, B.A.; Groven, L.; Son, S.; Yetter, R.A. Combustion Performance of Several Nanosilicon-Based Nanoenergetics. J. Propuls. Power 2013, 29, 1435-1444. [CrossRef]

10. Anil Rugunanan, R.; Brown, M.E. Combustion of Binary and Ternary Silicon/Oxidant Pyrotechnic Systems, Part III: Ternary Systems. Combust. Sci. Technol. 1993, 95, 101-115. [CrossRef]

11. Anil Rugunanan, R.; Brown, M.E. Combustion of Binary and Ternary Silicon/Oxidant Pyrotechnic Systems, Part IV: Kinetic Aspects. Combust. Sci. Technol. 1993, 95, 117-138. [CrossRef]

12. Piekiel, N.W.; Churaman, W.A.; Morris, C.J.; Currano, L.J. Combustion and material characterization of porous silicon nanoenergetics. In Proceedings of the 2013 IEEE 26th International Conference on Micro Electro Mechanical Systems (MEMS), Taipei, Taiwan, 20-24 January 2013; pp. 449-452.

13. Piekiel, N.W.; Morris, C.J.; Currano, L.J.; Lunking, D.M.; Isaacson, B.; Churaman, W.A. Enhancement of on-chip combustion via nanoporous silicon microchannels. Combust. Flame 2014, 161, 1417-1424. [CrossRef]

14. Plummer, A.; Kuznetsov, V.; Gascooke, J.R.; Shapter, J.G.; Voelcker, N.H. Laser shock ignition of porous silicon based nano-energetic films. J. Appl. Phys. 2014, 116, 54912. [CrossRef]

15. Kasi, S.R.; Liehr, M.; Cohen, S. Chemistry of fluorine in the oxidation of silicon. Appl. Phys. Lett. 1991, 58, 2975-2977. [CrossRef]

16. Yarrington, C.D.; Son, S.; Foley, T.J. Combustion of Silicon/Teflon/Viton and Aluminum/Teflon/Viton Energetic Composites. J. Propuls. Power 2010, 26, 734-743. [CrossRef]

17. Terry, B.C.; Son, S.; Groven, L.J. Altering combustion of silicon/polytetrafluoroethylene with two-step mechanical activation. Combust. Flame 2015, 162, 1350-1357. [CrossRef]

18. Terry, B.C.; Lin, Y.-C.; Manukyan, K.; Mukasyan, A.; Son, S.; Groven, L.J. The Effect of Silicon Powder Characteristics on the Combustion of Silicon/Teflon/Viton Nanoenergetics. Propellants Explos. Pyrotech. 2014, 39, 337-347. [CrossRef]

19. Valluri, S.K.; Bushiri, D.; Schoenitz, M.; Dreizin, E.L. Fuel-rich aluminum-nickel fluoride reactive composites. Combust. Flame 2019, 210, 439-453. [CrossRef]

20. Valluri, S.K.; Schoenitz, M.; Dreizin, E. Combustion of Aluminum-Metal Fluoride Reactive Composites in Different Environments. Propellants Explos. Pyrotech. 2019, 44, 1327-1336. [CrossRef]

21. Valluri, S.K.; Ravi, K.K.; Schoenitz, M.; Dreizin, E.L. Effect of boron content in B·BiF 3 and B·Bi composites on their ignition and combustion. Combust. Flame 2020, 215, 78-85. [CrossRef]

22. Valluri, S.K.; Schoenitz, M.; Dreizin, E. Bismuth fluoride-coated boron powders as enhanced fuels. Combust. Flame 2020, 221, 1-10. [CrossRef]

23. Valluri, S.K.; Schoenitz, M.; Dreizin, E. Combustion of Composites of Boron with Bismuth and Cobalt Fluorides in Different Environments. Combust. Sci. Technol. 2019, 1-16. [CrossRef]

24. Valluri, S.K.; Schoenitz, M.; Dreizin, E. Boron-Metal Fluoride Reactive Composites: Preparation and Reactions Leading to Their Ignition. J. Propuls. Power 2019, 35, 802-810. [CrossRef]

25. Valluri, S.K.; Monk, I.; Schoenitz, M.; Dreizin, E.L. Fuel-Rich Aluminum-Metal Fluoride Thermites. Int. J. Energetic Mater. Chem. Propuls. 2017, 16, 81-101. [CrossRef] 
26. Badiola, C.; Zhu, X.; Schoenitz, M.; Dreizin, E. Aluminum Rich Al-CuO Nanocomposite Materials Prepared by Arrested Reactive Milling at Cryogenic and Room Temperature. In Proceedings of the 47th AIAA Aerospace Sciences Meeting including the New Horizons Forum and Aerospace Exposition, Orlando, FL, USA, 5-8 January 2009. [CrossRef]

27. Ward, T.S.; Trunov, M.A.; Schoenitz, M.; Dreizin, E.L. Experimental methodology and heat transfer model for identification of ignition kinetics of powdered fuels. Int. J. Heat Mass Transf. 2006, 49, 4943-4954. [CrossRef]

28. Corcoran, A.; Mercati, S.; Nie, H.; Milani, M.; Montorsi, L.; Dreizin, E. Combustion of fine aluminum and magnesium powders in water. Combust. Flame 2013, 160, 2242-2250. [CrossRef]

29. Mohan, S.; Trunov, M.A.; Dreizin, E. Heating and Ignition of Metallic Particles by a $\mathrm{CO}_{2}$ Laser. J. Propuls. Power 2008, 24, 199-205. [CrossRef]

30. Chintersingh, K.-L.; Schoenitz, M.; Dreizin, E.L. Combustion of boron and boron-iron composite particles in different oxidizers. Combust. Flame 2018, 192, 44-58. [CrossRef]

31. Laval, J.P.; Champarnaudmesjard, J.C.; Frit, B.; Britel, A.; Mikou, A. BI7F11O5-A new ordered anion-excess fluorite-related structure withcolumnar clusters. Eur. J. Solid State Inorg. Chem. 1994, 31, 943-956.

32. Degen, T.; Sadki, M.; Bron, E.; König, U.; Nénert, G. The HighScore suite. Powder Diffr. 2014, 29, S13-S18. [CrossRef]

33. Laval, J.; Champarnaud-Mesjard, J.; Britel, A.; Mikou, A. Bi(F,O $)_{2.45}$ : An Anion-Excess Fluorite Defect Structure Deriving from Rhombohedral LnFO Type. J. Solid State Chem. 1999, 146, 51-59. [CrossRef]

34. McBride, B.J.; Gordon, S. Computer Program for Calculation of Complex Chemical Equilibrium Compositions and Applications II. Users Manual and Program Description; NASA RP 1311; NASA Glenn Research Center: Cleveland, OH, USA, 1996.

35. Kuriakose, A.K.; Margrave, J.L. Kinetics of Reaction of Elemental Fluorine. III. Fluorination of Silicon and Boron1. J. Phys. Chem. 1964, 68, 2671-2675. [CrossRef]

Publisher's Note: MDPI stays neutral with regard to jurisdictional claims in published maps and institutional affiliations.

(C) 2020 by the authors. Licensee MDPI, Basel, Switzerland. This article is an open access article distributed under the terms and conditions of the Creative Commons Attribution (CC BY) license (http://creativecommons.org/licenses/by/4.0/). 